University of Rhode Island

DigitalCommons@URI

Open Access Dissertations

1999

\title{
How Subject Characteristics Influence Attention Task Performance: A Structural Modeling Approach
}

Kristen A. McKiernan

University of Rhode Island

Follow this and additional works at: https://digitalcommons.uri.edu/oa_diss

\section{Recommended Citation}

McKiernan, Kristen A., "How Subject Characteristics Influence Attention Task Performance: A Structural Modeling Approach" (1999). Open Access Dissertations. Paper 930.

https://digitalcommons.uri.edu/oa_diss/930

This Dissertation is brought to you for free and open access by DigitalCommons@URI. It has been accepted for inclusion in Open Access Dissertations by an authorized administrator of DigitalCommons@URI. For more information, please contact digitalcommons-group@uri.edu. 
HOW SUBJECT CHARACTERISTICS INFLUENCE

ATTENTION TASK PERFORMANCE:

A STRUCTURAL MODELING APPROACH

BY

KRISTEN A. MCKIERNAN

A DISSERTATION SUBMITTED IN PARTIAL FULFILLMENT OF THE REQUIREMENTS FOR THE DEGREE OF

DOCTOR OF PHILOSOPHY

IN

PSYCHOLOGY

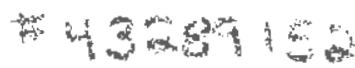

UNIVERSITY OF RHODE ISLAND 


\begin{abstract}
This research project presented and tested a theoretical model of auditory sustained attention. The model includes the personal, or subject characteristics that are believed to influence a person's ability to sustain attention. These characteristics are positive affect, negative affect, motivation, arousal, and concentration. Auditory sustained attention is represented by performance on a computerized continuous performance test (CPT); the CPT is widely used in both research and clinical settings. Three hundred and eleven participants were recruited for this study. Data from 286 of them were included in these analyses. All participants received some form of course credit for their participation. The measurement instruments used in this study include several paper and pencil tasks as well as an auditory CPT. Structural equation modeling methodology was used to analyze the plausibility of the hypothesized model of attention as well as several sub-models, each containing a subpart of the hypothesized model. The results revealed several strengths as well as weaknesses of the model. Overall, across the models tested, the hypothesized model seemed to best represent the cognitive process in question. An important finding was that the construct Arousal seemed to be well defined (58\% of the variance was accounted for) by three rather simple paper and pencil tasks. This construct has always been considered difficult to measure, thus the findings of this study may be very useful in this regard. The model, while not conclusive, provides important information about the proposed elements that work together to sustain attention, as well as for the specific measures used in this model to represent those elements. Future studies are needed to refine and improve on the measures so that the constructs will be better represented and understood.
\end{abstract}




\section{ACKNOWLEDGEMENT}

They say time flies when you are having fun. The last five years seem to have passed in a blink. I have truly enjoyed these graduate school years, and there are many people who have contributed to making this wonderful experience possible. This study is the culmination of several years of work. I want to start by thanking the group of people, my committee, who have had a huge impact on all of the major milestones in my course of study. These professors have served on committees for my thesis, comprehensive exams, and now this dissertation. Drs. Winnie Brownell, Jerry Cohen, Dom Valentino, and Grant Willis have been involved in all of these events. In addition, Drs. Sandra Ketrow and Charlie Collyer have served on both my thesis and oral comprehensive exam committees. Dr. Nelson Smith and Dr. Donna Schwartz-Barcott joined the committee for the defense of this dissertation. These are all people whom I admire for their dedication to teaching and quality research. I know that they have combined to teach me important lessons, improve my research skills, and help me to see how to approach an issue from new directions. I thank them for their time and effort, and importantly, for making me feel comfortable in stressful situations; all of our meetings, while challenging for me, had an atmosphere of respect and support which made them very positive learning experiences.

This project was a large undertaking, and there are several other people who helped to make it possible to complete it on time. First, two undergraduate research assistants, Vanessa Tucker and Dawn Vigue, assisted with the data collection. Without their help, the large amount of data needed for the model would never have been collected in only one semester. Both of these women willingly spent many hours each 
week collecting data, and I thank them for their time and effort. It was a pleasure to work with them. Once all the data were collected, it had to be entered into the computer. At a point in time when I still had many cases left to enter, but was so tired and stressed, two friends, Bonnie Flynn and April Duffy, came to the rescue. Not only did they volunteer to help, but they insisted on entering data despite their own busy lives. I truly appreciate their much needed help. Heartfelt thanks go to my parents who helped with the rather boring job of verifying the accuracy of the data entry for every single data point.

In general, this project and the whole graduate school experience would not have been possible for me had I not had the support of family and friends. I have a wonderful group of friends who have kept me from getting lost in a sea of tests and papers. Included in this group are the new friends that I've met at URI and whose friendships I hope will stand the tests of time and busy schedules. Their support, interest and helpful suggestions regarding what I've been doing for the last five years has meant a lot and allowed me to get the most out of the experience. My family has always been so supportive and has played a major role in allowing me to complete this program. Their love has shone through in so many ways from helping me move (again) and keeping my computer running to financial help and an always ready ear. I thank them all from the bottom of my heart.

One of the most important people to a graduate student is his or her major professor. I've been lucky to have the best. Dom Valentino has been my professor, advisor, and friend for the last five years and, I expect, for many more to come. He has guided me through the maze of graduate school requirements, taught me innumerable 
and invaluable lessons, supported me in all situations, shaped my philosophies of teaching and research, and guided me through a program of research that has resulted in this project. His warmth, concern and patience have made me a much happier and productive graduate student. To say thank you doesn't even begin to express the deep gratitude I feel for everything he has done for me. He has my complete respect and admiration.

This dissertation is dedicated to my parents, who have been a source of support and encouragement every step of the way for this and every other undertaking in my life. They have been so generous with their time, their love, their support and their enthusiasm, and this degree would not have been possible without them. Although I've never doubted that I could always count on them, they have proven it with actions and words time and time again. Thanks Mom and Dad, you've done so much to help me reach my goals. 
List of Tables ............................................................ vii

List of Figures ...................................................... viii

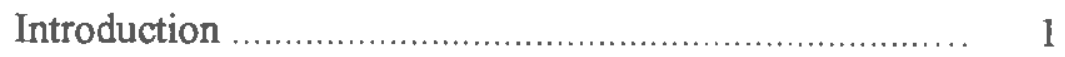

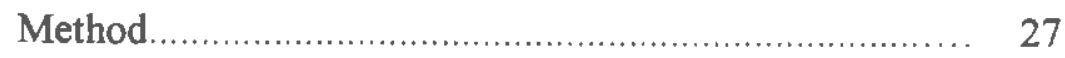

Results 1:Preliminary Data Analysis Procedures........... 32

Structural Modeling Criteria ............................ 34

Results 2: Structural Equation Modeling................... 36

Discussion ............................................................. 40

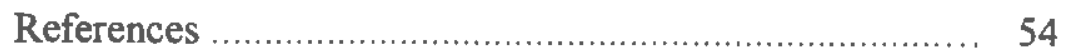

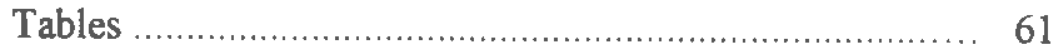

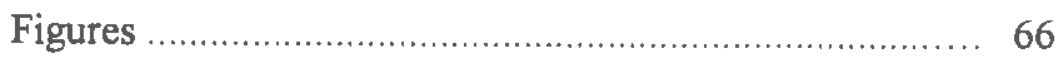

Appendix A: Positive Affect Negative Affect Scale........ 74

Appendix B: BIS/BAS Scales.................................. 75

Appendix C: Number Cancellation Task ......................... 76

Appendix D: Positive Sate of Mind Scales........................ 78

Appendix E: Visual Analog Mood Scales ........................... 79

Appendix F: Consent Form ……................................... 80

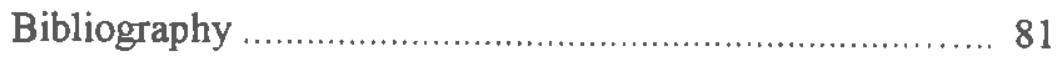




\section{LIST OF TABLES}

No. Title

Page

1 Description of Transformation Calculations for All Model Variables

61

2 Summary Statistics for All Model Variables Before and After

Transformation (When Applicable)

3 Results of Preliminary PCA on Transformed Variables

4 Correlations Among Transformed Variables Included in the Model

64

5 Paired T-TEST Results for Reaction Time Data - Minutes 5-8

65

versus Minutes 13-16 


\section{LIST OF FIGURES}

No. Title Page

1 Original Model of Auditory CPT Sustained Attention Using 66 Personal Variables

2 Full (All Paths) Model of Auditory CPT Sustained Attention Using 67 Personal Variables

3 Hypothesized Model of Auditory CPT Sustained Attention Using 68 Personal Variables

4 No Mood Model of Auditory CPT Sustained Attention Using 69 Personal Variables

5 No Motivation/Arousal Model of Auditory CPT Sustained Attention $\quad 70$ Using Personal Variables

6 No Concentration Model of Auditory CPT Sustained Attention Using Personal Variables

7 No Auditory Sustained Attention Model of Auditory CPT Sustained 72 Attention Using Personal Variables

8 Regression Model of Auditory CPT Sustained Attention Using Personal Variables 
Most researchers agree that attention is a complex and multivariate psychological construct, although issues regarding operational definitions and components have provided for many ongoing debates. The literature on sustained attention, or vigilance, is itself multifaceted and has a long history. Ballard (1996) has reviewed the factors affecting vigilance performance, and notes that "a variety of processes are involved in attention. These may include basic arousal, concentration, and sustaining attention over time" (p. 843)

This study presents a model that seeks to describe auditory sustained attention from a perspective of the personal characteristics believed to be involved, including the concepts of positive and negative valence, arousal, motivation, and concentration. This model was applied to data that were collected from several self-report measures of mood and activation and performance on a Continuous Performance Test (CPT) (Rosvold, Mirsky, Sarason, Brasome, \& Beck, 1956). It is important to remember that this study focuses mainly on sustained attention, which is one part of the multifaceted concept of attention. Since this model of sustained attention will identify the factors involved in attention from an information processing approach, and then provide support by identifying the anatomical areas of the brain that are involved, the theoretical basis for this model is founded in cognitive, neuro-, and physiological psychology.

Sustained attention, or vigilance, has been described as the ability of observers to maintain their focus of awareness and remain alert to stimuli for prolonged periods of time (Ballard, 1996; Davies \& Parasuraman, 1982; Koelega, Brinkman, Hendriks \& Verbaten, 1989; See, Howe, Warm \& Dember, 1995; Warm, 1984; Williams, 1986). According to a cognitive model of attention by Prather and Kaplan (unpublished 
manuscript), vigilance is a component of a generalized, but complex, construct of attention which subsumes several interrelated processes. Moderating variables include arousal and rate of processing, while specific functional aspects include orienting, maintenance of attention (i.e., vigilance), selective attention, expectancy, and integration (Prather \& Kaplan, unpublished manuscript).

\section{Subject Characteristics and Attention}

Complicating matters further, both arousal and vigilance can be components of models of emotion and motivation (Revelle, 1992). Recently, Lang (1995) described emotions as "states of vigilant readiness" with arousal and affective valence (positivity/negativity) as the strategic dimensions. According to this model, emotions can be thought of as "motivationally tuned" states of attention which are the products of evolution. In addition, in his hypothesis on motivation, Higgins (as cited in Azar, 1995) suggests a dimension called "regulatory focus" which interacts with valence and affects performance measures. These studies taken in conjunction with the model by Prather and Kaplan suggest that the links between emotion and attention may be valencemodulated arousal and vigilance.

Revelle (1992) has written extensively on the relationship between motivation, personality, and cognitive performance. He notes that it is usually assumed that the people who are subjects in human performance research are alert, optimally motivated, and have nothing else of importance on their minds other than the task at hand. Thus, Revelle (1992) continues, given these general assumptions, individual differences in cognitive ability are assumed to exist, but differences in motivation are generally ignored. 
Davies and Parasuraman (1982) also report that although the issue of motivation is considered to be a crucial determinant of performance, the vigilance theories to date have not emphasized its priority. Tomporowski and Tinsley (1996) agree that one explanation for the individual differences in performance on sustained attention tasks is motivation. Motivation can be viewed as a control process that alters or adjusts the parameters of the cognitive system to achieve maximum efficiency in executing responses (Revelle, 1992). Pribram and McGuiness (1975) use slightly different terms to say basically the same thing, "Effort can then be defined as the measure of the attention 'paid' to increase or maintain efficiency by reducing equivocation, that is, enhancing competency" (p.135).

The concept of concentration can be generally defined as focused attention on a task. In this study, this construct represents the individual's ability to understand what the task is and then be able to stay on-task for the testing period. It is important that they understand what the task is, that is, what they should be trying to do, first so that they can choose the correct information to attend/respond to and second so that when, and if, their attention deviates from the task, they will be able to return and continue with the CPT. Mirsky, Anthony, Duncan, Ahearn, and Kellam (1991) have proposed that there are several elements of attention, including the processes of focus, sustain, and shift. Mirsky et al, (1991) describe the focus element as the ability to select target information from and array of information for enhanced processing. This is basically the same way that this element is described for this study.

Shifting attention from one area of the environment to another is a natural function that contributes greatly to an organism's ability to remain aware of potential dangers in 
the surrounding environment. The nature of the CPT task, however, requires that this desire or inclination to shift attention be inhibited in order to maintain the focus of attention solely on one long and monotonous task. In this context, shifts that are made can be viewed as initiating lapses in sustained attention, or in another term, distractibility.

Mirsky et al., (1991) have also addressed this element of attention. They define their idea of "shift" as the ability to change attentive focus in a flexible and adaptive manner. Again, the definition for the construct, Concentration, in this model agrees with Mirsky et al.'s definition, but given the CPT task requirements, views these shifts of attentive focus in a more negative manner; the shifts represent a distraction from the task which the subject should be trying to inhibit or supress. In this study, the latent construct is labeled "Concentration" and, as described here, focused attention and distractibility are considered to be at opposite ends of the spectrum of behaviors that are represented by concentration. Therefore, the measures used to assess this construct can be viewed as either measures of focused attention or of distractibility; better performance indicates an ability to focus attention, while poorer performance indicates that the person is able to be distracted more easily.

\section{Measures of Sustained Attention: The CPT}

The most commonly used measure of sustained attention is a vigilance task known as a Continuous Performance Test (CPT), which is believed to be an objective measure of vigilance independent of verbal, perceptual, and other cognitive processes (Halperin, Sharma, Greenblatt, \& Schwartz, 1991). The CPT was originally developed by Rosvold, Mirsky, Sarason, Bransome, and Beck in 1956. CPTs are widely used as research tools 
and assessment instruments in clinical neuropsychological testing. During a CPT, participants are asked to respond to visual or auditory targets which require them to focus their attention on one task for an extended period of time, and respond to the targets by pressing a button. Correct responses to targets are called "hits." It is assumed that missed targets are attributable to lapses in attention (Halperin et al., 1991). However, it has been suggested that reaction time and false alarm rate may be finer measures of vigilance than accuracy (Halperin et al., 1991; See, Howe, Warm, \& Dember, 1995). Lang (1995) has suggested that performance as measured by reaction time may vary according to an arousal/emotional valence interaction. He believes that reaction time is affected by both arousal and valence for new stimuli, but by only arousal level for previously experienced stimuli (Lang, 1995).

\section{Attention Task Parameters}

A variety of factors impact an individual's ability to sustain attention, including time of day, memory load, background event rate, target discrimination type (successive versus simultaneous discrimination, sensory versus cognitive discrimination), sensory modality, number of sources to be monitored, heat stress, individual motivation, subject's locus of control, signal expectancy, spatial uncertainty, and signal complexity (Fisk \& Scerbo, 1987). Most of these factors are related to task parameters or environmental (situational) factors and have been studied extensively in the context of vigilance (Ballard, 1996; See et al., 1995); some were initially addressed by Parasuraman and Davies (1977) in their taxonomy of vigilance performance. Those factors that relate to subject characteristics have not been investigated as extensively as the task and environmental factors and are the focus of this study. 
Parasuraman and Davies (1977) proposed a taxonomy of vigilance performance that categorized vigilance tasks across two dimensions: type of discrimination (successive or simultaneous) and event rate (high or low). They defined successive tasks as those that required the participant to discriminate between stimuli by keeping a standard in working memory and comparing successively presented stimuli to that standard. Simultaneous tasks were defined as comparative judgment tasks in which a discrimination could be made based only on the information inherent in each individual stimulus. There is no requirement for working memory to be involved in this type of task. Event rate is determined by the rate of presentation of the background stimulus events in which the critical signals (targets) to be detected are embedded (See, et al., 1995). The taxonomy labels the event rate as "high" when the rate is 24 events/minute or higher, and "low" when the event rate falls below this mark.

Revisions to this taxonomy have explored the possibility of adding other dimensions such as type of stimuli used (cognitive versus sensory) and motivation (Koelega et al., 1989; See et al., 1995). See et al. (1995) use a rather broad definition of "cognitive" and "sensory" stimuli. A stimulus is considered cognitive if it is alphanumeric and as such, has meaning attached to it even if at a very basic level; it is sensory if it is not alpha-numeric (e.g., tone, volume, or other physical change to the stimulus) and therefore does not have "meaning". These variables (discrimination type, event rate, stimuli type, modality, etc.) can be considered "test variables," in that they represent variations in the testing parameters. In this study, these variables were held constant in order to establish a controlled environment and permit the investigation of the personal variables in question. Based on these qualifications, the CPT task used in 
this study is categorized as an auditory sucessive task employing cognitive stimuli at a high event rate.

\section{The Theoretical Model}

Before discussing the six constructs used in this model and believed to underlie the construct of sustained attention, the model of auditory vigilance being evaluated will be presented. The in depth descriptions of the constructs, the factors that measure them, and the psychometric support for those measures will be presented in later sections.

The model is comprised of six latent variables, Positive Valence, Negative Valence, Motivation, Arousal, Concentration, and Auditory Sustained Attention. The first five constructs are presumed to exert a strong influence on the last construct, Auditory Sustained Attention. A diagram of this model is presented in Figure 1. An overview of the constructs and measures follows:

1) Positive Valence is associated with feeling of positive mood and was measured by scores from three scales (Positive Affect, Joviality, and Fatigue) from the Positive Affect Negative Affect Scale - Expanded form (PANAS-X) (Watson \& Clark, 1992, 1994).

2) Negative Valence represents feelings of negative mood. This construct was measured using the Negative Affect, Sadness, and Serenity scales scores from the PANAS-X (Watson \& Clark, 1992, 1994). For both Positive and Negative Valence, the decision to chose specific PANAS scales, and grouping of the scales, was based on research results by the authors of the instrument.

3) The construct called Motivation represents the cognitive willingness to make the effort to sustain attention throughout the task. This was measured from scores on two 
scales, Reward Responsiveness and Drive, from the Behavioral Activation System (BAS) (Carver \& White, 1994). The third BAS subscale, Fun Seeking, was not used in this study. The scales were designed as a measure of the BAS, which is believed to be the physiological mechanism that controls appetitive motivation. A third measure came from the score on the Productivity scale from the Positive State of Mind (PSOM) scale (Horowitz, Adler, \& Kegeles, 1988). This scale represents the subject's self-reported ability to achieve a feeling of productivity. The actual description of this state of mind is "feeling able to stay at work until a task is finished, to do something new to solve problems, or to express yourself creatively" (Horowitz et al., 1988, p.478).

4) Arousal is conceived as the energy that is required for the effort to sustain attention. It was measured via the Tired and Tense scales from the Visual Analog Mood Scales (VAMS) (Stern, 1997). A third measure for Arousal was the Restful Repose scale from the PSOM (Horowitz et al., 1988). This scale represents the subject's ability to 'feel relaxed without distractions or excessive tension" (p.478).

5) Concentration can be thought of as a conscious focusing of attention and/or a resistance to distracting stimuli. This construct was measured by the number of correct cancellations made on a Number Cancellation Task (Moran \& Mefferd, 1959) during a specified time limit (150 seconds). This type of task has been used for many years as a method of assessing the capacity for sustained attention (Lezak, 1995). A second measure for this construct was the Focused Attention scale from the PSOM (Horowitz et al., 1988). This state of mind is described as "feeling able to attend to a task you want or need to do, without many distractions from within yourself' (p.478). Organisms have a natural tendency to shift attention across various aspects of their 
environment. In this model, since the subject was instructed to focus on the task and inhibit shifting, these shifts in focus represent distractibility, or an inability to maintain focused attention. The subject's tendency to engage in these shifts in attention was assessed by the Behavioral Inhibition System (BIS) score from the BIS/BAS scales (Carver \& White, 1994). The BIS is thought to regulate the aversive motivational system; activation of this system causes inhibition of movement toward goals (Gray, as cited by Carver \& White, 1994). Since the normal, ecologically effective goal of the individual is to shift attention to different aspects of the environment, the inhibition of this activity may be under the control of the activated BIS (Tucker \& Williamson, 1984). In the context of a CPT, a low level of BIS activation represents distractibility.

Auditory Sustained Attention was measured by three performance measures, accuracy, reaction time, and number of false alarms, on the CPT over a 12 minute period. All of these measures were recorded and/or calculated by the CPT scoring program. The following paragraphs provide a more in-depth discussion of the constructs mentioned above. The measures will then be presented in more detail followed by the psychometric properties supporting the reliability and validity of those measures.

\section{Positive and Negative Valence}

The concept of affect or mood has become an integral part of many psychological theories. Leventhal and Tomarken (1986) posit that mood affects cognitive performance. For example, depression is thought to impair cognitive functions such as learning and memory, while positive moods often appear to facilitate cognitive functioning. 
Self-report measures of mood have been developed to address many different kinds of research questions. The two strongest dimensions that appear consistently from studies that use self-report mood measures are the bipolar dimensions of positive and negative mood (Watson \& Tellegen, 1985). These two factors can be found using a variety of descriptor items and rotation methods. One of the main problems with trying to describe mood states is that many mood terms are not pure markers of either positive or negative affect. Some early research by Watson and Tellegen (1985) indicates that the constructs of positive affect and negative affect are consistent, stable, and independent products of self-reported mood measures. Based on this evidence, Watson, Clark and Tellegen (1988) developed and validated a brief measure of positive (PA) and negative affect (NA) called the PANAS scales. This scale was then further developed into the PANAS-X or Expanded form (Watson \& Clark, 1994), which was the instrument used in this study.

Leventhal and Tomarken (1986) indicate that the most influential theory in the previous twenty years of emotion research has been the cognition-arousal theory that is attributed to Schachter and his colleagues. This theory states that "an emotional state is the product of the interaction between two components, physiological arousal (characterized as heightened sympathetic activation) and a cognition about the cause of that arousal" (Leventhal \& Tomarken, 1986, p. 567). They continue to explain that since arousal is non-specific, it determines only the intensity of the response, while the cognitions determine their quality and direction. This theory, although an influential one, has not been strongly supported by experimental evidence. 
Some relatively recent research by Tomarken, Davidson, Wheeler and Doss (1992) has indicated that individual differences in anterior brain asymmetry are linked to differences in basic dimensions of emotion, specifically positive affect and negative affect. Their study used electroencephalographic (EEG) procedures to assess individual differences in people. In developing their hypothesis, they noted the evidence from the literature for a relationship between asymmetrical activation in anterior cerebral regions and concurrent emotional state. Specifically, increased activation of anterior regions in the left hemisphere is associated with heightened positive affect, decreased negative affect, or both. Increased activation in anterior areas of the right hemisphere is linked to heightened negative affect, decreased positive affect, or both. They noted that there is also evidence in the literature indicating that individual differences in hemispheric asymmetry can predict performance on cognitive tasks. Tomarken et al. (1992) combined these observations and hypothesized that, "individual differences in anterior asymmetry index differing neural thresholds for affective responses to stimuli and differing mechanisms for the self-regulation of emotion over time" (p.676). They used the PANAS (general version), and specifically predicted that people who had a stable pattern of increased relative left anterior activation would report greater PA, but lesser NA when compared to individuals who showed a pattern of relative right anterior activation. Their results generally supported this prediction, with a significant difference for PA, but not for NA (Tomarken et al., 1992).

\section{Arousal}

Arousal refers to a variety of physiological and behavioral states characterized by a degree of excitation or energy mobilization (Duffy, as cited in Parasuraman, 1984). In 
this model, arousal refers to the availability of energy that is needed in the effort to sustain attention. Generally, states of arousal are identified as varying on a continuum from coma to excited emotion. Transitions between stages of arousal are accompanied by a variety of changes in the autonomic (ANS) and central nervous systems (CNS) (Cohen \& O'Donnell, 1993). Since vigilance tasks are generally long and monotonous, they often induce drowsiness or feelings of boredom in the subject. This has led to a fair amount of research focusing on whether physiological signs of lowered arousal are related to the typically observed vigilance decrements. In general, the results have indicated weak or inconsistent relationships between ANS measures and vigilance performance, and more robust findings with electroencephalogram (EEG) and related measure of CNS activity (Parasuraman, 1984; Valentino, Arruda, \& Gold, 1993). Valentino et al., (1993) conducted a study that employed the same CPT that was used in this study. They found that individuals who had better performance (indicated by no decrease in accuracy over the duration of the CPT) had more anterior beta power and less posterior alpha and theta power (indicating a greater level of arousal) than did the group of poorer performers on the vigilance task. In this model of vigilance, arousal measures were derived from self-reported levels of energy.

Regulation of arousal is one of the functions of the reticular activating system (Pribram \& McGuiness, 1975). The reticular formation is located in the lower regions of the brain stem and midbrain. It receives sensory information that is on the way to the cortex, as well as projections from the spinal cord, cerebellum, and cortex. The destruction of the reticular formation can lead to a loss of consciousness, while electrical stimulation can awaken a sleeping animal and produce an EEG pattern of 
desynchronization. Based on these physiological findings, the reticular formation has been described as a sentinel which serves to arouse the cortex, forming part of an alarm system called the ascending reticular activating system (ARAS) (Parasuraman, 1984).

Level of vigilance has been shown to be related to level of arousal, therefore, it may be that this aspect of vigilance performance is controlled by neural pathways forming part of a frontal cortex-ARAS network (Parasuraman, 1984, Revelle, 1992). Mirsky (1996) suggests that sustaining a focus of attention on some aspect of the environment is the major responsibility of the rostral midbrain structures, including the mesopontine reticular formation and the midline and reticular thalamic nuclei. The Pribram and McGuiness model (cited by Cohen \& O’Donnell, 1993; Koelega, 1996; Mirsky, 1996; Parasuraman, 1984) suggests that the arousal system includes the mesencephalic reticular formation (MFR) as well as more rostral and caudal structures from the medial parts of the spinal cord up to and including the hypothalamus. Parasuraman (1984) reports that Pribram and McGuinness refer to this group of structures as the corebrain arousal system, and suggest that it is controlled by excitatory and inhibitory pathways coordinated by the amygdala. As of the publishing of Parasuraman's 1984 article, there was no firm evidence to support the control of level of vigilance by these pathways, but he notes that it is a plausible and heuristic hypothesis.

\section{Motivation}

Motivation has been described as the vital link between knowing and doing, between thinking and action, and between competence and performance (Revelle, 1992). From a general perspective, decrements in task performance may be explained in terms of motivational effects. According to Revelle (1992), motivational states can 
be categorized in several different ways. Often, he notes, the distinction has been made between the affective direction (positive and negative) and energetic intensity (energetic and tense) of motivation. Revelle (1992) cites Thayer as associating energetic arousal with approach behavior and tense arousal with avoidance behavior. This theory is heavily based on Gray's $(1972,1981)$ theory of brain function and behavior. As described by Carver and White (1994), this theory proposes "two dimensions of personality (anxiety proness and impulsivity) which represent individual differences in the sensitivity of two neurological systems in their responses to relevant environmental cues. One system regulates aversive motivation; the other regulates appetitive motivation" (p.319). The aversive motivation system is called the Behavioral Inhibition System (BIS) and the appetitive motivation system is called the Behavioral Activation System (BAS). Carver and White (1994) have developed the BIS/BAS scales as measures of dispositional BIS and BAS sensitivities. The construct Motivation in the model tested in this dissertation was measured by two of the three scales that represent components of the appetitive motivation system, or BAS. The three scales are labeled Drive, Reward Responsiveness, and Fun Seeking (which is not used here). The Drive scale consists of items chosen to assess the persistent pursuit of desired goals. The Fun Seeking scale contains items that reflect both a desire for new rewards and a willingness to approach a potentially rewarding event on the spur of the moment. The Reward Responsiveness scale focuses on positive responses to the occurrence or anticipated occurrence of reward. The BIS scale was used as a measure of concentration, or, more accurately, the ability to inhibit shifts in attention and will be discussed in greater detail in that section of this dissertation. According to Carver and White (1994), BIS and 
BAS represent separate neurological structures which can be distinguished both pharmacologically and by brain lesions, thus they are considered orthogonal systems. This means that there can be many, many combinations of proportions between the individual sensitivity for each system; someone who is high on one system may have any level of the other.

The Behavioral Activation System has a less clearly identified neural basis than the BIS. It is thought, however, that the catecholaminergic pathways, especially the dopaminergic ones, have a central role in this system (Gray, as cited in Carver and White, 1994). This system is described as being sensitive to signals of reward, nonpunishment, and avoidance of punishment. Activation of the BAS causes the individual to move toward goals (Carver \& White, 1994). They note that it is Gray's opinion that the BAS also has a role in the experience of positive feelings (mood).

\section{Concentration}

In the study by Mirsky et al., (1991), a Letter Cancellation task was one of tests chosen to measure the focusing element of attention. The present study also used a cancellation task (Moran \& Mefferd, 1959) to measure the Concentration construct. As noted by Mirsky et al., this type of test has been used in attention studies for the past hundred years. The Cancellation test requires the subject to focus attention on a display and respond efficiently to the targets while ignoring other non-target information. According to Lezak (1995), it is easier to separate attention, concentration, and tracking in theory than it is in practice. Purely attentional impairments appear as distractibility or an impaired ability to focus behavior, regardless of the patient's intention. Lezak (1995) continues by saying that intact attention is a required precursor for both 
concentration and mental tracking activities. Attention therefore can be assessed by observing general behavior and performance on tests involving concentration and tracking (Lezak, 1995). The number cancellation task by Moran and Mefferd (1959) qualifies as a tracking test. The score used by Mirsky et al. was the mean number of correct cancellations over a series of trials. In this study, the score represents the number of correct cancellations for a single trial which has a time limit of 150 seconds.

Mirsky et al., (1991) have proposed that the inferior parietal, superior temporal, and striatal regions each have a role in the focusing or concentration element of attention. They support their suggestions, stating that, "the first two are major multimodal sensory convergence areas in the brain. The posterior parietal cortex, in particular, has connections with sensory, limbic, thalamic, and brain stem reticular areas as well as with motor regions of the brain" (p. 131). They also note that support for the choice of these areas comes from the observation of neglect following parietal lesions, particularly on the right side, and reports of mild attentional problems following temporal lobe seizures or lobectomy for seizures.

The PSOM (Horowitz et al., 1988) scale for Focused Attention is another measure for the Concentration construct. The PSOM (Positive State of Mind) scale is a paper and pencil survey that contains brief descriptions of six states of mind. The participant uses a 4-point (0-3) scale to rate their own ability to achieve each state of mind. The authors claim that these states of mind can be examined individually or as a composite for positive states of mind in general. This study used three of the states (Focused Attention, Productivity, and Restful Repose) as independent measures for three different constructs (Concentration, Motivation, and Arousal, respectively). The PSOM scales 
have consistently showed an inverse relationship with anxiety and with measures of stress. Each state of mind was also shown to be independent, that is, ease of achieving one state does not depend on the ease with which one or more of the other states are reached. Given that the psychological testing environment can be stressful and/or anxiety producing for some individuals, it seemed reasonable to include these measures in this study as indicators of how likely the person was able to achieve a positive state of mind given the situation. Adler, Horowitz, Garcia, and Moyer (1998) concluded that, depending on the individual's characteristics and situation, the ability to achieve some states of mind may be more or less affected by stress. This model is trying to account for individual differences, therefore these subscales were included as measures.

As previously mentioned, the BIS score from the BIS/BAS scale (Carver \& White, 1994) was used as a measure of Concentration. Much of the theory and theoretical support for the BIS/BAS scales has already been presented, but there are a few points specific to the Behavioral Inhibition System. According to Carver and White (1994), this aversive motivational system is comprised of the septohippocampal system, its monoaminergic afferents from the brainstem, and its neocortical projection in the frontal lobe. This system is described as being sensitive to signals of nonreward, punishment, and novelty. Activation of the BIS inhibits the individual from moving toward goals (in this case, the individual's goal was to shift attention according to natural tendencies) (Carver \& White, 1994). They note that it is Gray's opinion that the BIS also has a role in the experience of negative feelings. 


\section{Reliability and Validity of the Measures}

PANAS-X. The Positive Affect Negative Affect Scales, Expanded Version (PANAS-X) (Watson \& Clark, 1992, 1994) is a sixty item survey that produces several mood or affect subscale scores (see Appendix A). From the original PANAS (Watson, Clark \& Tellegen, 1988), the two higher level scales, one for Positive Affect (PA) and one for Negative Affect (NA), were retained. These scales reflect the valence (positive or negative states) of the mood descriptors. According to Watson et al. (1988),

Positive Affect reflects the extent to which a person feels enthusiastic, active, and alert. High PA is a state of high energy, full concentration, and pleasurable engagement, whereas low PA is characterized by sadness and lethargy. In contrast, Negative Affect (NA) is a general dimension of subjective distress and unpleasant and unpleasurable engagement that subsumes a variety of aversive mood states, including anger, contempt, disgust, guilt, fear, and nervousness, with low NA being a state of calmness and serenity (p.1063).

Research has indicated that these scales represent orthogonal dimensions of affect, and they have been said to have high internal consistency. There is also evidence of convergent and discriminant validity for the scales (Watson et al., 1988).

The PANAS-X also provides measures for several lower level scales that address the specific content (or individual affects) of the PA and NA states. The specific lower level scales used as measures in this model are: Joviality, Fatigue, Sadness, and Serenity. Watson and Clark (1994) have tested the PANAS-X quite extensively and have concluded that there is strong evidence for internal consistency, construct validity, and the hierarchical arrangement of the scales. 
Each PA and NA scale consists of ten items (mood adjectives), and the individual is asked to rate each on a five point Likert scale according to the extent they have experienced each mood state during a specified time frame. For this study, the subject was instructed to use the time frame of "right now", that is, they rated each item based on how they were feeling right at that time. The ten mood adjectives that comprise the PA scale are: attentive, interested, alert, excited, enthusiastic, inspired, proud, determined, strong, and active. The ten descriptors for the NA scale are: distressed, upset, hostile, irritable, scared, afraid, ashamed, guilty, nervous, and jittery. (Watson et al., 1988). Each of the specific affect scales is composed of between 3 and 8 items. The Sadness scale is one of the basic negative emotion scales and is composed of 5 adjectives: sad, blue, downhearted, alone, and lonely. The Joviality scale is one of the basic positive emotion scales, and it has the following 8 descriptors: happy, joyful, delighted, cheerful, excited, enthusiastic, lively, and energetic. The Fatigue and Serenity scales fall under the category of other affective states because they load less heavily on either the PA or NA factors. The Fatigue scale contains 4 items: sleepy, tired, sluggish, and drowsy, while the Serenity scale has 3 items: calm, relaxed, and at ease. On the PANAS-X form given to the participants, the 60 items are intermingled in a random manner. The final scale score is the sum of the individual items for that scale.

These particular scales were chosen as measures in this model for several reasons. First, the PA and NA scales have been found to together account for about one-half to three-quarters of the common variance in self-rated mood (Watson \& Clark, 1994). Preliminary factor analyses conducted on PANAS-X data $(\mathrm{N}=65)$ previously collected by our laboratory have supported the existence of the two definable factors that 
correspond to positive affect and negative affect. The ability of the PANAS-X to evaluate mood in the time frame of "right now" makes this instrument particularly appropriate as a measure of the subject's mood directly before they are administered the CPT. The other scales were chosen based on the same preliminary analyses mentioned above. A factor analysis (with oblique rotation to allow for correlated factors) using the subscale scores for all the scales mentioned above revealed two factors (positive affect and negative affect) with the appropriate subscales loading on each (PA, Joviality, and Fatigue at $.94, .84$, and -.48 respectively on Positive Affect, and NA, Sadness and Serenity at $.92, .85$, and -.74 respectively on Negative Affect). These loadings agree with the PANAS theory presented by Watson and Clark $(1992,1994)$.

BIS/BAS Scales. The BIS/BAS scales (Carver \& White, 1994) survey asks the subject to rate each of 25 statements on a 4 point Likert scale to indicate their agreement with that statement (see Appendix B). All BIS items reference potentially punishing events and evaluates how the person responds to them. The focus is on the experience of anxiety in situations in which there are cues of punishment. The BAS items have a more divergent focus with statements that emphasize the persistent pursuit of desired goals (Drive) or a positive response to the occurrence or anticipation of a reward (Reward Responsiveness).

The data from over 700 college students who completed the BIS/BAS scale were collected by Carver and White (1994) and were submitted to a factor analysis with oblique rotation. The analysis produced four factors, which together accounted for $49 \%$ of the total variance. Each factor corresponds to one of the four subscales previously described (including Fun Seeking). Additionally, the analysis revealed that the BIS 
scale was relatively independent of the BAS scales (correlations of -.12 with Drive, .28 with Reward Responsiveness, and -.08 with Fun Seeking), thus supporting the theory of independent physiological systems. Each BAS scale (Fun Seeking, Reward Responsiveness, and Drive) contributes to assessing an individual's Behavioral Activation System. They are moderately correlated with each other (range of .34 to 41), but each is thought to provide unique information. Only the two most relevant scales (Drive and Reward Responsiveness) were included in this study.

The construction and subsequent testing of the BIS/BAS scales by Carver and White (1994) indicate that they are psychometrically sound, showing good convergence and divergence with other measures. For example they report that some or all of the BAS scales correlated significantly with MMPI Hypomania, an Extroversion measure, PANAS Positive Affect, and GTS Positive Temperament. The BIS scale was not correlated with any of these measures, but was significantly correlated with the Manifest Anxiety Scale (MAS), CPI Socialization scale, PANAS Negative Affect, GTS Negative Temperament, and a measure of BIS developed by other researchers. Additionally, as mentioned, the two BAS scales have a correlation of .34 with each other, while each has a low correlation with the BIS scale (correlations range from -.08 to .28$)$.

Number Cancellation Test. The Number Cancellation Test (Moran \& Mefferd, 1959 ) is considered to be a measure of the ability to focus or concentrate on a task. It is a paper and pencil task in which the subject is instructed to cancel all the targets in a display of numbers. The numbers are presented on two pages, each with 25 rows of 30 digits, which were selected from a table of random numbers. The first digit in each row 
is circled to indicate that it is the target digit for that row (see Appendix C). The target numbers are randomly interspersed in each row (Lezak, 1995). There are 141 target digits in the test. Over the years, there have been many different versions of this type of test used for clinical and research purposes. The score is the number of correctly canceled digits in two-and-one-half minutes.

PSOM. This study included three of the PSOM states (Focused Attention, Productivity, and Restful Repose) as independent measures for three different constructs (Concentration, Motivation, and Arousal, respectively) (see Appendix D). The initial presentation of this scale (Horowitz et al., 1988) included data from 187 undergraduates that indicated that the original hypotheses were supported. The PSOM scales showed evidence of internal consistency (Cronbach alpha $=.77$ ) as well as convergent and divergent valididty. The PSOM scale was, as predicted, negatively correlated with the negative mood states from the Profile of Mood States (POMS) (McNair, Lorr, \& Droppleman, 1981) and positively correlated with the positive mood state of 'vigor'. Also as predicted, the PSOM scale was negatively correlated (-.46) with the Taylor Manifest Anxiety Scale (Taylor, 1953). A follow-up study by Adler et al. (1998) provided additional validation of the PSOM scale. Two additional college samples as well as two samples of pregnant women (one of which was about to undergo a stressful amniocentesis procedure) were studied. The results of this series of studies support the utility of using the PSOM scale as an assessment of positive subjective experiences and a reflection of exposure to stress.

VAMS. The Visual Analog Mood Scales (VAMS) are designed to be brief, valid measures of internal mood states in clinical populations, including those for whom 
attention, comprehension, and verbal capabilities have been compromised (Stern, 1997; Stern, Arruda, Hooper, Wolfner, \& Morey, 1996). They have been found to have high test-retest reliability and excellent convergent and discriminant validity. The VAMS consist of eight analog scales representing eight different emotions (happy, sad, tired, energetic, confused, angry, tense, and afraid). Only the Tired and Tense scales were used in this study (see Appendix E). Previous research in our laboratory has indicated that the Energetic scale often loads heavily on Positive Affect as well as on Arousal, therefore it was not used here. Each scale has one face placed at either end of a vertical 100 millimeter line. The top face represents neutral, and is labeled as such, while the bottom face represents one of the emotions, and is also clearly labeled. Each person is instructed to draw a line that bisects the $100 \mathrm{~mm}$ line at the point that they feel most accurately described their mood at that time. The score is determined by measuring in millimeters the distance from the neutral end of the line to the individual's mark.

CPT Measures. Based on the CPT literature, the traditional CPT measures of accuracy, reaction time, and number of false alarms were collected. False alarms can be thought of as representing the response bias of the subject. All CPT measures were recorded and/or computed automatically by a computer.

\section{Structural Equation Modeling}

Structural equation modeling (SEM) is the most general of the multivariate techniques. Using this methodology, a researcher can examine the linear relationships between a set of variables that are believed to be related in a particular manner. SEM combines the best features of factor analysis, multiple regression, and path analysis into a single method. 
The rationale behind using SEM include that it allows for a more complex and therefore potentially more realistic representation of the phenomenon of interest, in this case that phenomenon is auditory sustained attention. It accomplishes this by allowing for latent (unobservable) constructs and also for allowing multiple indicators (measures) for each construct. Multiple indicators should, if they are valid and reliable measures, provide a better, stronger representation of the construct that would a single indicator. SEM also increases complexity of the analysis by allowing the model to contain direct and indirect effects or relationships between the variables. In this way, mediating effects can be analyzed. A third manner in which SEM can provide a more realistic model is in its ability to perform clustering and multiple regression procedures simultaneously, thus separating measurement error from the effects of variable relationships. It should be assumed that all measures contain some degree of error, and this method takes that error into account.

The procedures involved in SEM start with the development of a theory. While this may seem obvious, it is a crucial step in the research process that can, in the end, make or break the model. The development of a theory requires a literature review and a good understanding of the concepts included in it. The previous sections of this introduction have presented the results of such a search.

Once the theory has been developed, the variables that compose each part of the theory must be operationalized. It is important that each variable is clearly defined in terms of the construct it represents, the measures for each construct must be determined to be valid and reliable, and the relationships between the constructs must be specified. The next step is to translate the theory into a model that can be drawn as a path diagram 
(see Figure 1). Construction of the path diagram also provides an opportunity to identify miss-specifications or weaknesses in the model as well as to prepare the model to be transcribed into a format, generally a set of regression equations, that is usable by the computer software.

Since the operationalization of the variables is such a key element of the theory building process, the following paragraphs will present some of the important SEM concepts that must be considered during this phase. This information will also be important in assessing the overall potential of the theory that has been presented in this study. There are two kinds of variables that can be specified, measured variables (MV), which are directly observable, and latent variables (LV), which are not directly observable. LVs are generally defined by the MVs that identify each one. The relationships between the variables can be either directional or non-directional. Direct effects are relationships that are specified to be in a certain direction (i.e., LV $\rightarrow$ LV). Indirect effects are relationships between variables that do not have a specified direction (i.e., MV $\leftrightarrow$ MV). Based on how the directional relationships are specified in the diagram, each variable can be defined as exogenous or endogenous. An exogenous variable receives no directional influences from any other variable in the model, while an endogenous variable receives directional influences from at least one other variable.

Another step in the process is to identify the parameters. These consist of variances, covariances, and weights. Variances represent the amount of variability within an exogenous variable (note: endogenous variables such as Concentration can also have variances, but they are not parameters because the variance is considered to be implied by the influences of the other variables that directly or indirectly relate to 
it.). Covariances represent the amount of covariation between two exogenous variables (note: endogenous variables (e.g. Motivation and Arousal) are not permitted to have these non-directional relationships because the covariation is implied via the influences of the other variables.) The weights are representative of the relationships between variables that share directional relationships; these weights are basically regression weights. Each parameter must be designated as either fixed (given a value, usually 1.0) or free (free to be estimated). Another consideration is that every LV in the model must be given a scale. A scale must be provided because LVs are not directly observed, therefore they do not already have scales. This can be accomplished by fixing one indicator for each latent variable at 1.0 , thus establishing a metric for the LV. This then enables the remaining variables that measure that $\mathrm{LV}$ to be estimated.

Another important consideration is whether the model is identified. Identification is related to the number of degrees of freedom ( $\mathrm{df}$ ) for the model. Different types of models have different methods for computing $\mathrm{df}$, but generally it is the number of parameters to be estimated minus the elements in the variance/covariance matrices. If the model is underidentified $(\mathrm{df}<0)$, then it cannot be analyzed. The model is considered to be identified if $\mathrm{df}=0$, and overidentified if $\mathrm{df}>0$; either condition is acceptable.

The next step in the procedure is to submit the model to computer analysis; in this case, EQS 5.7b (Student Version) (Bentler, 1995) software performed the analysis. The computer will produce a variety of values that need to be analyzed by the researcher to determine the overall fit, or how well the data fit the hypothesized model. There are several aspects to consider, including theory, parsimony, and empirical evidence. The 
theory represents the strength of the theoretical basis of the model. Parsimony asks whether the model is as concise as it could be, or is there a simpler explanation that is acceptable. The empirical evidence is the results from the computer analysis and is discussed more specifically in the Structural Equation Modeling results section.

In summary, confirmatory analysis (CFA), which is one type of SEM, is appropriate for this type of investigation because it can handle the multiple measures and latent constructs that are believed to underlie this complex concept called sustained attention. Briefly, confirmatory factor analysis is based on the premise that observable variables are imperfect indicators of latent constructs which cannot be directly measured. When there is more than one indicator variable for each latent construct, CFA allows them to be clustered (based on theory) in such a way that the extent to which a particular set of data "confirms" what is theoretically believed to be the underlying structure of the constructs can be evaluated. This means that the researcher must make an a priori hypothesis about the underlying structure of the constructs and then use CFA to evaluate whether or how well the observed data "fit" the specified model (Mueller, 1996). Stated another way, a confirmatory factor analysis specifies the relationships of the observed measures to their posited underlying constructs, as well as specifying the causal relationships between the constructs according to a theory (Anderson \& Gerbing, 1988).

\section{METHOD}

\section{Participants}

A total of 311 participants were recruited for this study from the University of Rhode Island, Kingston campus. Prior to any analyses, twenty-five participants had to 
be deleted from the sample for a variety of reasons, including 3 due to technical (equipment) difficulties; 2 because they reported a loss of consciousness greater than 5 minutes in their history; 10 due to their current medications (e.g., stimulants, antidepressants, and anxiolitics); 6 due to reported neurological conditions (e.g., epilepsy, narcolepsy); 1 because of a muscular disorder (dystonia); and 3 because they did not provide complete information for all tasks. Data from the remaining 286 participants (220 women and 66 men, mean age $=19.2$ years, $\mathrm{SD}=2.5$, range $=18$ to 42) were included in the subsequent analyses. The majority (91\%) of the participants were right handed. While both undergraduate and graduate students participated, the majority of those tested were undergraduates (freshmen $=53 \%$, sophmores $=25 \%$, juniors $=16 \%$, and seniors $=5 \%$ ). All students received some form of course credit for their participation. Although $6(2 \%)$ participants reported that they considered themselves to have below normal hearing ( 4 because they had tubes in their ears as children and 2 due to slight hearing losses), all participants indicated that they could hear the letter stimuli without any problems during the CPT practice and test. All participants were treated in accordance with the "Ethical Principles of Psychologists and Code of Conduct" (APA, 1992).

\section{Equipment}

A Gateway 2000 IBM compatible personal computer administered the computerized auditory CPTs and collected and scored the performance measures. The stimuli were presented over stereo headphones. Sound Blaster Pro software was used to articulate the letters and tones. During all test sessions, a white noise generator produced a consistent level of noise loud enough to mask noise from outside the 
laboratory. The white noise was generated from a position located approximately $21 / 2$ feet directly behind the seated subject. Participants responded to target stimuli by pressing a hand-held, continuous interrupt button that was connected to the computer. A tape player was used to play a cassette tape that presented a distraction condition. The player was located on top of the white noise speaker, and the volume was set so that the distraction was not loud enough to mask the CPT task. The distracter tape itself was constructed with the appropriate time lengths of distraction (4 minutes) and silence (12 minutes) so that once started, it played throughout the CPT without requiring any attention from the experimenter which could distract the subject. The data collected during the distraction period (minutes 9-12 of the CPT) were not included in this study.

\section{Tests \& Questionnaires}

Each participant completed, in order, the consent form, BIS/BAS scales, PSOM Scale, Number Cancellation Task, VAMS, and PANAS-X prior to taking the CPT.

\section{CPT Task}

This study employed a sixteen-minute audio letter version of the CPT. The letter task consisted of a semi-random series of letters of the alphabet ("w" was the only letter not included) as stimuli. Participants pressed a button once every time they heard a letter that was identical to the preceding letter; two identical stimuli in a row constituted a target. The letter task was chosen over a similar tone task (uses tones instead of letters) also used in our laboratory because a previous study in our laboratory (Reeve, 1997) had found that there is a learning curve associated with the tone task. When participants hear the tone task, they require approximately the first six minutes of the testing to learn the task. There is no learning curve associated with the letter task 
(Reeve, 1997). By presenting the letter task, the data from all parts of the test including the first six minutes are valid. It is especially important to be able to use the early data because they may be best represented by the pre-test mood data.

The letter stimuli were presented at an onset-to-onset rate of .5 seconds. Previous research in our laboratory has shown that at slower onset-to-onset rates a ceiling effect is observed for accuracy, a floor effect for false alarms, and the relationships between mood and performance measures diminish. This last effect was found during an unpublished study from our laboratory which used multiple regressions to investigate the relationship between four mood variables (happy, sad, tired, and energetic) from the Visual Analog Mood Scales (VAMS) (Stern, 1997) on each of three CPT performance measures (reaction time, false alarm rate, and accuracy) for each of two sets of data. The only difference between the two sets of data was that the stimuli (letters) were presented at different onset-to-onset times (.5 and .75 seconds, respectively). Paired ttests between the groups indicated that there were no significant differences on any of the seven variables. Regression analyses for the .5 second group revealed two significant regressions, one for reaction time, and one for false alarm rate (McKiernan, Reeve, \& Valentino, 1996). The four VAMS variables accounted for approximately $29 \%$ of the variance in reaction time and $24 \%$ of the variance in false alarm rate. When these analyses were repeated for the .75 second group, no significant results were found.

Over the course of the sixteen-minute task, the participants heard 1920 stimuli, 160 of which were target stimuli. Targets semi-randomly occurred at an average rate of one every six seconds. There were no instances in which a target was immediately followed by another target (i.e., a $\underline{a} \mathrm{~b} \underline{\mathrm{b}}$ ). Data from the first 8 minutes and last 4 minutes of the 
CPT were combined (averaged) for use in this study.

\section{Procedure}

Participants were tested individually. Each participant was tested only once. The testing process began when the participant signed the consent form (see Appendix F) upon arriving for the study. After that, the participant completed the BIS/BAS, PSOM, Number Cancellation Task, VAMS, and PANAS-X. CPT testing began by directing the subject to sit in the testing chair and reading the instructions to explain the task. Participants were given the headphones over which the stimuli were presented, and allowed to adjust them for fit and comfort. The response button was held in their preferred hand (writing hand). Each person was instructed to use the thumb of his or her preferred hand to depress the button. The room lights were extinguished, and the white noise machine and tape player turned on. After a brief practice sequence, the CPT task was presented to the individual. After the CPT, the participants were debriefed to complete the session.

\section{Computerized Scoring}

The measures of attention performance collected by the computer were: percent of "hits," correct responses to targets referred to as accuracy; "false alarms", errors of commission; and response reaction time. A scoring program designed by Kevin Smith (University of Rhode Island, 1996) scored the CPT data. The scoring program allowed a maximum reaction time of up to 1300 milliseconds after target onset for a response to a target to be categorized as a hit. The program also allowed the researcher to specify certain "blocks" of stimuli to be scored. This particular feature was used to analyze performance that occurred during the 12 minutes of the non-distraction (silent tape) 
condition. The scored and calculated data were imported into Excel 97 and SPSS for Windows 9.0 (SPSS Inc., 1998) for statistical analysis and EQS 5.7b (Student Version) (Bentler, 1995) for the CFA of the model.

\section{Hand Scoring}

The BIS/BAS, Number Cancellation Task, VAMS, PSOM, and the PANAS-X were hand scored. For the BIS/BAS and PSOM scales as well as the PANAS-X, the subject's responses were entered into an Excel spreadsheet, which was programed to compute the subscale scores. The Letter Cancellation Task was scored using a template. The VAMS are scored by hand using a standard metric ruler. The score was determined by measuring in millimeters the distance from the neutral end of the line to the subject's mark.

\section{RESULTS 1: PRELIMINARY DATA ANALYSIS PROCEDURES}

The data from 286 participants were evaluated for violations of the multivariate assumptions underlying structural equation modeling. Differences in scale values of the measurement variables can affect EQS efficiency and accuracy in minimizing the fitting function (Raykov, Tomer \& Nesselroade, 1991). In an attempt to avoid this and reduce the non-normal aspects of the data, several variables were transformed (see Table 1). After transformation, all variables had skew and kurtosis values between -1 and +1 . Homoscedasticity was also evaluated by examining the scatterplots for all variables. Additionally, one subject was deleted from the EQS analyses based on a high contribution to multivariate kurtosis, thus the EQS sample size was 285. Summary statistics for all model variables are presented in Table 2. 
A preliminary principle components analysis (PCA) was performed on the three indicator variables for each of the six latent constructs. Each PCA (except Concentration) produced one factor that had strong loadings for the indicators, and accounted for $46.5 \%$ to $70 \%$ of the variance in the construct. The PCA for the Concentration construct produced two factors; the three indicators each loaded moderately on the first factor and accounted for $37 \%$ of the variance. Focused Attention (PSOM1) had a very low loading on the second factor while NC and BIS had moderately high loadings; $34 \%$ of the variance in the second factor was accounted for. The exact loadings for each PCA are located in Table 3. These preliminary results indicated that the constructs were adequately defined and the indicators were clustering together according to the theory. Further examination of the correlation matrix (see Table 4) revealed that the PANAS scales Fatigue, Joviality, Sadness and Serenity were significantly correlating with several variables that were indicators for other constructs. In order to eliminate the problems that these correlations would cause during the evaluation of the model, it was decided to eliminate these four indicators and modify the model such that Positive Valence and Negative Valence each became single indicator variables measured by the Positive Affect and Negative Affect (respectively) scales from the PANAS (see Figure 2). In addition, the correlation matrix revealed that Focused Attention (PSOM1) and Productivity (PSOM2) were not correlating with either of the other two indicators for their respective constructs. Based on this weakness, it was decided that these indicators would also be deleted.

A series of nested models were then evaluated using EQS 5.7b (Student Version) (Bentler, 1995). Although the programs for each model would run to 
completion, the results could not be evaluated due to the presence of condition codes produced by the software program. These codes indicated that there were problems due to either non-normal data, sample size, or a miss-specification in the model. It was determined that several of the constructs were actually underidentified (the missspecification). When a construct is represented by two measures, it will be underidentified. This is because there are only three data points and four parameters, which results in the degrees of freedom equaling -1 . Also, further investigation revealed that the coefficient alphas for the remaining constructs were low ( .47 for Auditory Sustained Attention, .52 for Concentration, and .69 for Arousal). Based on these missspecifications and low alphas, it was determined that there were structural problems and indicators were not holding together and defining each construct as well as the initial PCAs had indicated, thus explaining the production of the condition codes. The solution was to eliminate several of the weaker indicators, thus leaving the Arousal construct intact, altering the Motivation construct to be a single indicator variable defined by the Drive scale from the BAS, defining the Concentration construct as a single indicator variable represented by the BIS scale, and altering the Auditory Sustained Attention construct to also become a single indicator variable defined by reaction time (see Figure 3). Thus, all constructs were adequately identified.

\section{STRUCTURAL MODELING CRITERIA}

The raw data were used as input for the model analyses. At this point in the analyses, there were no instances of missing data. The method of estimation of the unknown parameters was maximum likelihood (ML), the most widely used estimation method that has demonstrated robustness against moderate violations of normality. 
The empirical fit of the model for each data set was evaluated against a series of criteria, including the chi-square to degrees of freedom ratio; the comparative fit index (CFI) (Bentler, 1990); the non-normed fit index (NNFI) (Bentler \& Bonett, 1980), the value of the average absolute standardized residuals (AASR); the significance of individual parameters, including regression coefficients between constructs and factor loadings between latent constructs and indicators; and the amount of explained variance. A model is considered to empirically "fit" the observed data when the chisquare to degrees of freedom ratio is less than 2.0 ; the comparative fit index and nonnormed fit index values are greater than .90 ; the AASR value is less than .06; hypothesized parameters are significant; and the amount of explained variance is substantial (Hoyle \& Panter, 1995).

In this study, there was only one model (referred to as the hypothesized model) that had been constructed based on a theory. The process of theory development requires that the model be assessed not only for theoretical consistency, but also for parsimony. To accommodate this requirement, a series of nested models (or partial models) (see Figures 2-8) were evaluated. Each partial model leaves out some portion of the full model, which is the model that contains all possible pathways (see Figure 2). Examination of the results for each partial model can help identify the importance of the contribution of that particular missing component, as well as address the issue of parsimony. Parsimony requires that of two or more equally well fitting models, the one with the fewest parameters is the preferred model. The last model (see Figure 8) is a regression-like version of all five constructs on Sustained Attention; this can provide information on the strength of each construct as a predictor of Sustained Attention. 


\section{RESULTS 2: STRUCTURAL EQUATION MODELING}

The results of the structural modeling analyses are presented graphically by each of the respective figures (see Figures 2-8).

The full model (see Figure 2) represents all possible relationships between the constructs and attention task performance. Since many of the paths in this model are also specified in the hypothesized model, there is some theoretical support for this particular model, however it has very poor parsimony. The empirical evidence is as follows. The chi-square to degrees of freedom ratio was moderately low, the fit indices were split, with the CFI acceptable, but the NNFI was low; and the AASR was acceptable. Seven of the 11 pathways were not significant, and neither was the correlation between Positive Valence and Negative Valence. The proportion of explained variance in Auditory Sustained Attention $\left(\mathrm{R}^{2}=.02\right)$, Motivation $\left(\mathrm{R}^{2}=.05\right)$ Concentration $\left(\mathrm{R}^{2}=.15\right)$ and Arousal $\left(\mathrm{R}^{2}=.59\right)$ revealed small, medium, large and very large effect sizes, respectively (Cohen, 1992). All residuals were less than .2, indicating that there were no missing or miss-specified paths. The chi-square value $\left(\chi^{2}(13)=\right.$ 43.19) was, however, less than .05 , indicating that there is a significant difference between the covariance matrix implied by the model and the actual data covariance matrix (Hoyle, 1995). This issue of a significant chi-square statistic is true for all of the subsequent models.

The second model to be tested represents the hypothesized model that is the focus of this study. This model (see Figure 3) hypothesizes that Positive Valence and Negative Valence, while not correlated with each other, each influence Motivation and Arousal. The literature regarding behavioral activation (BAS) does not support the path 
from Negative Valence to Motivation (measured by a BAS scale); this path was included in the model, but not expected to be significant. Motivation and Arousal each influence Concentration. Concentration, now represented by the BIS score, represents the individual's ability to inhibit their natural tendency to respond to a distraction or switch the focus of attention. Concentration influences CPT performance (Auditory Sustained Attention as measured by CPT reaction time).

This model has good theoretical foundations, and better parsimony than the full model. The empirical evidence is moderately supportive of the theory. The chi-square to degrees of freedom ratio was low, the fit indices were high, and the AASR was low, all of which are considered good results. One pathway (Motivation to Concentration) was not significant, and the pathway from Concentration to Auditory Sustained Attention was significant only at the .10 level. All other paths were significant, except Negative Valence to Motivation, which was not expected to be significant. The proportion of explained variance in Concentration $\left(\mathrm{R}^{2}=.14\right)$ and Arousal $\left(\mathrm{R}^{2}=.58\right)$ revealed large and very large effect sizes, respectively (Cohen, 1992), while Motivation $\left(\mathrm{R}^{2}=.04\right)$ and Auditory Sustained Attention $\left(\mathrm{R}^{2}=.01\right)$ both revealed small effect sizes. All residuals were less than .2 , indicating that there were no missing or miss-specified paths. The chi-square value $\left(\chi^{2}(18)=46.19\right)$ was significant.

The third model that was tested left out the mood constructs (see Figure 4), Positive Valence and Negative Valence. This model does not have strong theoretical support due to the lack of influence from the mood variables. Although the model is parsimonious, it does not have good empirical support. The chi-square to degrees of freedom ratio was high, the fit indices were very low, and the AASR was high. One 
pathway (Motivation to Concentration) was not significant, and the pathway from Concentration to Auditory Sustained Attention was still significant only at the .10 level. The other path and all factor loadings were significant. The proportion of explained variance in Concentration $\left(\mathrm{R}^{2}=.16\right)$ and Auditory Sustained Attention $\left(\mathrm{R}^{2}=.01\right)$ revealed large and small effect sizes, respectively (Cohen, 1992). There were 6 residual values greater than .2 , indicating that there were missing or miss-specified paths. Each of these residuals represented a path that was related to either Positive Valence or Negative Valence and variables still in the model. The chi-square value $\left(\chi^{2}\right.$ $(22)=201.54)$ was significant.

The fourth model left out the Motivation and Arousal constructs (see Figure 5). This model does not have strong theoretical support due to the lack of influence from Motivation and Arousal. Although the model is more parsimonious than the first two models, it does not have good empirical support. The chi-square to degrees of freedom ratio was high, the fit indices were very low, and the AASR was high. All paths and factor loadings were, however, significant (the path from Concentration to Auditory Sustained Attention was significant at the .10 level). The proportion of explained variance in Concentration $\left(\mathrm{R}^{2}=.08\right)$ and Auditory Sustained Attention $\left(\mathrm{R}^{2}=.01\right)$ revealed medium and small effect sizes, respectively (Cohen, 1992). There were 7 residual values greater than .2 , indicating that there were missing or miss-specified paths. Interestingly, none of the missing paths involved Motivation. The chi-square value $\left(\chi^{2}\right.$ $(22)=209.64)$ was significant.

The fifth model left out Concentration (see Figure 6). Due to the novelty of adding this construct to a model of sustained attention, the degree of theoretical support 
for this model is unclear. Concentration is representing the ability to focus attention, and a focus element is commonly included in more general models of attention (Mirsky et al, 1991; Prather \& Kaplan). This model is more parsimonious than the first two models, but less parsimonious than the third and fourth models. It does not have good empirical support. The chi-square to degrees of freedom ratio was fairly high, the fit indices were low, and the AASR was acceptable. The paths from Motivation to Auditory Sustained Attention and from Arousal to Auditory Sustained Attention were not significant. The proportion of explained variance in Arousal $\left(\mathrm{R}^{2}=59\right)$, Motivation $\left(\mathrm{R}^{2}=.05\right)$ and Auditory Sustained Attention $\left(\mathrm{R}^{2}=.01\right)$ revealed very large, medium and small effect sizes, respectively (Cohen, 1992). There were 3 residual values greater than .2 , indicating that there were some missing or miss-specified paths. Interestingly, none of the missing paths indicated a need for a path from Motivation to Concentration. The chi-square value $\left(\chi^{2}(19)=80.92\right)$ was, like all previously described models significant.

The sixth model was basically the same as the theorized model with the exception that Auditory Sustained Attention was left out (see Figure 7). This model has weaker theoretical foundations because the construct of real interest has been deleted. If, however, there is the possibility that Concentration and Auditory Sustained Attention may be overlapping constructs, this version of the model may have merit. It has better parsimony than the full model, and the empirical evidence is as good as it is for the hypothesized model. The chi-square to degrees of freedom ratio was low, the fit indices were high, and the AASR was low. One pathway (Motivation to Concentration) was not significant. All other paths were significant, except Negative Valence to 
Motivation, which, again, was not expected to be significant. The proportion of explained variance in Concentration $\left(\mathrm{R}^{2}=.14\right)$ and Arousal $\left(\mathrm{R}^{2}=.58\right)$ revealed large and very large effect sizes, respectively (Cohen, 1992). All residuals were less than .2, indicating that there were no missing or miss-specified paths. The chi-square value $\left(\chi^{2}(19)=49.83\right)$ was significant.

The last model was the regression model in which all variables directly influenced Auditory Sustained Attention (see Figure 8). Given that all of these constructs are discussed in the attention literature as influencing factors, this model should have fairly strong theoretical support. It is fairly parsimonious, although the correlations among the constructs add quite a few parameters. The empirical support has both strong and weak points. The chi-square to degrees of freedom ratio was moderately low, the fit indices split with the CFI acceptable and the NNFI too low, and the AASR was low. No regression paths were significant. All correlations between the constructs were significant, with the exception of Positive Valence and Negative Valence, and Drive and Motivation. The proportion of explained variance in Auditory Sustained Attention $\left(\mathrm{R}^{2}=.02\right)$ revealed a small effect size (Cohen, 1992). There were no residual values greater than .2 , indicating that there were no missing or miss-specified paths. The chi-square value $\left(\chi^{2}(10)=42.76\right)$ was, like all the others, significant.

\section{DISCUSSION}

The present study was designed to examine the relationships among mood, motivation, arousal, ability to concentrate, and performance on an auditory sustained attention task. More specifically, the hypothesis tested (see Figure 3) was that positive and negative mood would affect levels of motivation and arousal, which in turn would 
affect ability to concentrate or focus attention, and this would influence performance on a CPT, which is a typical vigilance task. The analysis included a series of alternative models in order to better interpret the results and understand the contributions of the individual elements of the model.

The preliminary results indicated that some changes to the measurement structure of the model were required. Several indicator variables had to be deleted based on correlations (or lack thereof) with other variables (see Table 4) and related weaknesses in the factor structures. These deletions reduced the structure of the model to a simpler format in which all constructs except Arousal were represented by only a single measured variable. This was not the ideal structure for the model because single indicator variables do not have the power of reliability and validity that can come with a well-represented multi-indicator construct. For most of the simplified constructs, two of the three measures worked well together, but the issue of identification of the model dictated that there be either three or one measure per construct. The decision to retain one indicator over another was made based on theory, and examination of the correlation matrix. For Motivation, the decision to retain Drive was influenced by problems associated with the other indicators. Specifically, the excessive number of significant correlations between the Productivity PSOM variable and other variables in the model, and the likely possibility that Reward was influenced by Heywood cases, which are instances in which the estimated parameters for the variable fall outside the range of possibilities (i.e., -1 to +1 ) indicated that these two measures could not be trusted. For Concentration, The PSOM variable, Focused Attention, was deleted due to the same correlation problems mentioned above. Number Cancellation was deleted 
because it was not correlated with any other variable, and therefore was not easily interpretable. Auditory Sustained Attention had a very low coefficient alpha (.47), indicating that the measures were not holding together well to define the construct, or in other words, the internal consistency of each construct was low (Hoyle \& Smith, 1994). This result was not expected because many previous studies in this lab have used these measures together with good results. Additionally, the research presented in the literature generally uses all three of these measures to represent CPT performance (Halperin et al., 1991; Lang, 1995; Mirsky et al., 1991; See et al., 1995). The decision to retain Reaction Time as the single indicator was based on the theories of Halperin et al. (1991), Lang (1995), and See et al. (1995), who speculate that reaction time may be a more sensitive measure of vigilance than accuracy or false alarms. To better understand this variable, it is important to note that the maximum reaction time, 1300 milliseconds in this study, was assigned to every missed target during the scoring procedure.

The issue of a significant chi-square value needs to be addressed. While this is not an ideal result, it is not a major problem either. The significant chi-square value indicated that the two matrices in question were different from one another. In the larger view of SEM, this is just one of the fit criteria that is used to evaluate the model. In fact, the chi-square statistic is considered to be one of the poorest indicators of fit because it is affected by sample size (Bentler \& Bonett, 1980). The Comparative Fit Index and other criteria mentioned in the results section are considered to be much more stable fit indices and are therefore preferred over the significance of the chi-square statistic. Anderson and Gerbing (1988) address this issue, stating that "the measurement model may sometimes be judged to provide acceptable fit even though the 
chi-square value is still statistically significant. This judgement should be supported by the values for the normed fit index and the other fit indices, particularly the root mean square residual index in conjunction with the number of large normalized or standardized residuals" (p. 417).

The results of the confirmatory factor analysis for each model will now be discussed with the emphasis on each model's contribution to understanding the usefulness of the hypothesized model.

The full model (see Figure 2), which contains all possible paths, provided support for the structure of the hypothesized model because all the "extra" paths in this model were not significant. All paths to Auditory Sustained Attention which bypassed Concentration were not significant, indicating the possibility that Concentration could be a mediating factor between the first four constructs and Auditory Sustained Attention.

The results for the hypothesized model (see Figure 3 ) indicate that there is support for this model. The empirical evidence was good overall, with the biggest weakness being the small amount of variance (1\%) in Auditory Sustained Attention that is accounted for by the other constructs. Approximately $14 \%$ of the variance in Concentration was accounted for by the four constructs Positive Valence, Negative Valence, Motivation, and Arousal. It is also important to note the very large amount (58\%) of variance explained in Arousal. This particular result will be discussed in more detail later. The significance of the regression path from Concentration to Auditory Sustained Attention is reported as significant at the .10 level. The z-value associated with this path (1.91) is actually very close to the alpha $=.05$ criterion level of 1.96 . 
Concentration is being defined as the ability to inhibit the natural tendency to shift the focus of attention. Interestingly, it was not, in any model, significantly influenced by Motivation. This finding does not support the idea that decrements in task performance may be explained in terms of motivational effects. A possible explanation for this finding may be found in Revelle's (1992) discussion of motivation. As mentioned in the introduction, he notes that motivation is often described in terms of affective direction and energetic intensity. This model of attention contains both constructs of affective direction (Positive and Negative Valence) and energetic intensity (Arousal). Perhaps these three constructs are accounting for these dimensions that are generally associated with Motivation. This could explain why the Motivation construct itself is not contributing much; by having the other three constructs in the model, these dimensions are already being represented.

A second explanation for the finding discussed above is as follows. The power of the model was compromised by the reduction of most of the constructs to single indicator constructs. This specifically applies to the case of the non-significant path between Motivation and Concentration. The correlation table revealed that the single indicators (Drive and BIS), representing these two constructs, were not significantly related. Generally, it is desirable for indicators of different constructs to have low or no correlation with each other. However, since these indicators are now the only measures for the constructs, the model becomes compromised; it would not be possible for the SEM analyses to find a significant relationship between two completely uncorrelated measures.

Another finding to note is that Positive Valence has a negative relationship with 
Arousal, while Negative Valence has a positive relationship. This seems counterintuitive until one notices that the more negative measures, Tired and Tense, load positively on Arousal, and Restful Repose, which has a more relaxed connotation, loads negatively. According to the research presented by the authors of the PSOM scales (Horowitz et al., 1988), the PSOM scale correlates negatively with measures of negative mood and anxiety and positively with measures of positive mood. Thus, the relationships depicted by this model are supported by the literature.

Arousal is positively related to Concentration. In terms of the measures, this can be explained as increases in arousal are related to increased BIS scores; higher BIS scores mean the person is more able to inhibit actions (such as shifting attention), and is therefore able to concentrate better or at a higher level than someone who has a low BIS score. A possible problem with this interpretation is that, as defined, Arousal has a negative connotation (tiredness and tense), and the general assumption is that people who score high in these areas are generally not better at concentrating than someone who reports a more relaxed/positive level of arousal. Perhaps the addition of a measure that connotes a positive energy level would be beneficial in helping to define the Arousal concept. The difficult aspect of carrying out this suggestion is that many adjectives that qualify as describing positive energy levels also load very highly on the Positive Valence construct. It was exactly this problem that prevented such a measure from inclusion in this study.

Auditory Sustained Attention, as mentioned, has very little of its variance explained by these constructs. The variance in Concentration (14\%), on the other hand, is fairly well explained. The difference between these two constructs is really the 
dimension of time; Concentration is the ability to focus attention on a task stimulus by stimulus and inhibit the natural tendency to shift that attention to another task, and Auditory Sustained Attention requires this ability over an extended time period. It is possible that, in this study, these constructs and their measures are not sensitive enough to discriminate the difference. Given the measures available, these two constructs may be too similar or overlapping. Concentration may be accounting for the majority of explainable variance, thereby leaving Auditory Sustained Attention with very little to explain. Previous studies, including McKiernan, Reeve and Valentino $(1996,1997)$, have produced CPT data (using the same test parameters) that have correlated with measures of mood and arousal, whereas in this study, the CPT variable, specifically reaction time, does not correlate with any of the other measures. A potential reason for this discrepancy will be discussed later.

Another puzzling finding involves the positive relationship between Concentration and Sustained Attention. Ordinarily, a positive relationship is exactly what would be expected, however, in this model Auditory Sustained Attention is measured by reaction time on the CPT. Reaction times have to be thought of in the reverse, that is, increases in reaction time actually represent a slower performance and decreases in reaction time indicate faster performance. Given this measurement system, it was expected that the relationship between Concentration and Sustained Attention would be negative; higher levels of concentration would produce faster (lower) reaction time performance.

The subsequent models each leave out some element or elements of the hypothesized model. This technique is referred to as testing nested models. Evaluation 
of the nested models in reference to the hypothesized model can facilitate the process of determining the contributions of each element to the model in question. Examination of the residual matrix for the model in which the mood constructs were left out (see Figure 4) revealed that there were several missing relationships. All of these relationships involved influences from Positive Affect and Negative Affect to Arousal. This is evidence to support the inclusion of the mood constructs. Although the deletion of the mood constructs negatively affected the fit criteria for the model, the amount of explained variance in Concentration and Auditory Sustained Attention and the significance of the tested paths did not change. It is important to remember that a model must have theoretical support; since theory supports the inclusion of the mood constructs, it can be determined that this model is not as strong as the hypothesized model.

In Figure 5, the paths from Positive Valence and Negative Valence to Concentration are both significant, however, the amount of explained variance in Concentration is only about half as much as it is when Motivation and Arousal are included. The directions of these relationships (positive or negative) agree with the findings from the hypothesized model. This supports the theory that the mood constructs do in fact have some influence on Concentration. It appears that the better representation is for the influence of the mood variables on Concentration to be mediated by Arousal (and possibly to some degree by Motivation) as depicted by the hypothesized model.

The sixth figure provides support for the possibility that the CPT measure, reaction time, is not, for this study, an adequate measure for Auditory Sustained 
Attention. Even though Concentration has been deleted from the model, the amount of explained variance in for Auditory Sustained Attention has not changed as might be expected if the sole problem was that these two constructs are overlapping in term of representing attention. The path from Arousal to Concentration is significant in all of the other models, but here the path from Arousal to Auditory Sustained Attention is not significant. Possible reasons for the problem with reaction time will soon be discussed. The results from this model also support the hypothesized model as best representing (from these tested choices) the relationships among these variables.

From Figure 7, it becomes apparent that there is indeed a problem with the Auditory Sustained Attention construct. The empirical support for this model is as strong as for the hypothesized model, yet the focus of the model has been deleted. This model technically, then, has better parsimony than the hypothesized model but poorer theoretical support. It is suspected that the CPT measures were affected by the distraction condition during minutes $9-12$ of the CPT, and thus were not representing the construct as they have in the past.

The regression version of the model (see Figure 8) clearly indicated that none of the direct relationships between the constructs and Auditory Sustained Attention were significant. This, too, supports a preference for the mediational-style model. Also of note from this model and not available from any of the other models, is the finding that Motivation and Arousal were, as expected, significantly correlated. The complete lack of significant direct effects in this model were not expected. Previous research in this laboratory (McKiernan, Reeve \& Valentino, 1996, 1997) as well as other studies in the literature (Ballard, 1996; Lang, 1995; Revelle, 1992) have found relationships between 
at least some of these constructs and sustained attention. One possible explanation is, again, in this study, the CPT measures may not have been collected under optimal conditions.

The issue regarding the CPT measures that has been mentioned several times refers to the general lack of a vigilance decrement over the 16 minute task. Basically, after 16 minutes there should be a significant decline in the CPT measures accuracy and reaction time. These finding are among the most well established results in all of the attention research. During this study, a distraction condition was presented during minutes 9-12. Only the data from the "non-distraction" (i.e., minutes 1-8 and 13-16) condition were actually included in this study. Examination of the CPT measures that were expected to show a decrement (accuracy and reaction time) over the entire test period, however, reveals a rather atypical pattern. Other studies in this laboratory using the same test parameters, except for the distraction, have produced the expected vigilance decrement across both measures (McKiernan, 1997; Reeve, 1997). In this study, however, the inclusion of the distraction condition appeared reduce or prevent the decrements. Focusing specifically on reaction time, it would be expected that the average reaction time during the last four minute period of the test (minutes 13-16) would be slower than during the second four minute block (minutes 5-8 right before the distraction). A paired t-test (see Table 5) on these data revealed that the average reaction time during the final four minutes was actually significantly faster than during the second four minutes. The lack of the typical vigilance decrement (termed latency decrement when referring to reaction time) may have negatively affected the use of this measure as representing Auditory Sustained Attention. Vigilance and latency 
decrements are the hallmark of sustained attention, and the lack of the typical decrement is likely to be an important factor in explaining the weakness of the Auditory Sustained Attention construct in this model. Without the decrement, some of the important, and perhaps more easily accountable, variation in performance has been removed, leaving the model less powerful.

The large amount of variance explained in the construct Arousal (58\%) was an important finding in this study. Arousal has long been considered to be a very difficult concept to measure. The literature reports that the use of autonomic nervous system measures (e.g., blood pressure and heart rate) do not consistently correlate well with vigilance performance (Parasuraman, 1984). EEG results are more robust, but are rather time intensive to implement. The results from this study indicate that a fairly powerful estimation of level of arousal may be achieved using some quick and simple paper and pencil tasks. The three measures that were used to represent the construct in this study include the Tired and Tense scales from the Visual Analog Mood Scales (VAMS) (Stern, 1997) and the Restful Repose scale from the Positive State of Mind Scales (PSOM) (Horowitz, et al., 1988). Reliability of the measures as indicated by the coefficient alpha value of .69 is a bit low, but certainly suggests that further testing of these measures as representing arousal is warranted. As previously discussed, the addition of a measure for a "positive" energy may aid interpretation of the construct.

The amount of explained variance in Concentration (14\%) was also consistently impressive. The fact that this construct was represented by only a single variable greatly reduces the immediate utility of this finding. Further investigation into the BIS scale is necessary. It is also possible that other attention tasks could be added as 
indicators of the construct. The Stroop test (Stroop, 1935) is one example of a popular task that may be appropriate.

Points that have not yet been addressed directly are the issues related to construct validity. The use of latent constructs opens the researcher to the possibility of misnaming the constructs. It is important to recognize that simply naming latent constructs does not insure that the name is an accurate reflection of what the construct actually represents. Furthermore, the measured variables may not actually be measuring what the researcher intends. Both of these threats to validity are very real in this study. Other potential problems that must be acknowledged include the possibility of mono-operation and mono-method biases. All but one of the constructs in this model have single indicators; ideally multiple items should be used to increase construct validity. Most of the data in this study were collected by means of paper and pencil tasks; ideally multiple methods will increase the ability to dissociate the influence of the method on the effect and the effect itself.

This study, while not conclusive, has contributed some very important new information to the field of attention research. A model like this one that integrates several different personal characteristics in an attempt to explain variations in vigilance task performance is unprecedented in the literature. These results indicate that the model's mediational format may be superior to a regression format. This is reflective of the complex interactions that are involved in attentional processes. These results support the theory that each of these constructs contributes to influencing attention task performance, thus providing a starting point for new studies. Future studies should investigate the inclusion of better indicators for Motivation and Concentration. This 
study should also be replicated, but without the distraction condition. Hopefully, this will improve the Auditory Sustained Attention construct in terms of being able to include all of the three typical CPT performance measures as indicators and increasing the amount of explained variance.

Based on the literature, the Number Cancellation task (Moran \& Mefferd, 1959) was expected to be a strong indicator for Concentration. Previous research in this lab using a Letter Cancellation Task (Talland, 1965) revealed a significant correlation between CPT accuracy and Letter Cancellation accuracy (McKiernan, Purvenus, Tucker, \& Valentino, 1999). The format of this Number Cancellation task required the subject to focus on a new target numeral for each line of the task. The face validity seemed high and it was expected that this would provide a fairly sensitive measure of distractibility. Exactly the opposite appeared to occur. A subsequent study in our lab this past semester involved 42 undergraduate participants and produced the same results for the Number Cancellation task; it still did not correlate with any other CPT measure nor did it correlate with a verbal version of the Stroop (Stroop, 1935). Future studies might investigate the properties of this test and its relationship with other measures of concentration, with the hope of including it in future models.

Perhaps more variability within the subject pool would enhance the power of the model. The majority of the participants in this study were freshmen. This limits the ability to generalize the results.

Ideally, future studies would include patient populations; the CPT is used to diagnose attention deficits in patient populations, therefore it is crucial to include them in the research process. It is important to note that the CPT is not just a research tool; it 
is a common instrument used to clinically assess attention. If this model, or a similar one, can account for some substantial proportion of the variability in performance on the CPT, one of the most important applied contributions may be in the area of improving the diagnostic accuracy of the CPT. Many times, the need for an assessment of attention is a result of some type of injury or impairment of normal functioning. It is reasonable to assume that a person who has sustained an injury serious enough to produce attention deficits (or at least the possibility of such deficits) may also be suffering from mood, motivation, arousal and concentration problems. A patient who has an injury to the frontal lobes, for instance, may present such a pattern of problems. Instead of administering a CPT to this patient and interpreting the results solely in terms of accuracy, reaction time and number of false alarms, the availability of a model such as the one proposed in this study, one that can account for the fact that the patient is upset over the injury and may be depressed and have low motivation may improve the interpretability of the CPT results in light of the impact that these mood and/or motivation problems may have on CPT performance. 


\section{REFERENCES}

Adler, N.E., Horowitz, M., Garcia, A., \& Moyer, A. (1998). Additional validation of a scale to assess positive states of mind, Psychosomatic medicine, 60, 26-32.

American Psychological Association. (1992). Ethical principals of psychologists and code of conduct. American Psychologist, 47, 1597-1611.

Anderson, J.C, \& Gerbing, D.W. (1988). Structural equation modeling in practice: A review and recommended two-step approach. Psychological Bulletin, 103(3) 411423.

Azar, B. (1995, November). Attitude affects memory, decisions, and performance. Monitor, p.27.

Ballard, J.C. (1996). Computerized assessment of sustained attention: A review of factors affecting vigilance performance. Journal of Clinical and Experimental Neuropsychology 18(6), 843-863.

Bentler, P.M. (1990). Comparative fit indexes in structural models. Psychological Bulletin, 107(2), 238-246.

Bentler, P.M. (1995). EQS Structural Equations Program. Encino, CA: Multivariate Software, Inc.

Bentler, P.M. \& Bonett, D.G. (1980). Significance tests and goodness-of-fit in the analysis of covariance structures. Psychological Bulletin, 88, 588-606.

Bentler,P.M. \& Wu, E.J.C. (1995). EQS for window's users guide. Encino. CA: Multivariate Software, Inc. 
Carver, C.S., \& White, T.L. (1994). Behavioral inhibition, behavioral activation and affective responses to impending reward and punishment: The BIS/BAS scales. Journal of Personality and Social Psychology, 67(2), 319-333.

Cohen, J. (1992). A power primer. Psychological Bulletin, 112, 155-159.

Cohen, R.A. \& O'Donnell, B. F. (1993). Physiological substrates of attention. In A.E. Puente \& C.R. Reynolds (Series Eds.) \& R.A. Cohen (Vol. Ed.), Critical issues in neuropsychology: The neuropsychology of attention (pp. 115-144). New York: Plenum Press.

Davies, D.R., \& Parasuraman, R. (1982). The psychology of vigilance. New York: Academic Press.

Fisk, A., \& Scerbo, M. (1987). Automatic and control processing approach to interpreting vigilance performance: A review and reevaluation. Human Factors, 29(6), 653-660.

Gray, J.A. (1972). The psychophysiological basis of introversion-extroversion: A modification of Eysenck's theory. In V.D. Nebylitsyn \& J.A. Gray (Eds.), The biological bases of individual behavior (pp. 182-205). San Diego, CA: Academic Press.

Gray, J.A. (1981). A critique of Eysenck's theory of personality. In: H.J. Eysenck (Ed.), A model for personality (pp. 246-276). Berlin: Springer-Verlag.

Halperin, J.M., Sharma, V., Greenblatt, E., \& Schwartz, S. (1991). Assessment of the continuous performance test: Reliability and validity in a nonreferred sample. Psychological Assessment: A Journal of Consulting and Clinical Psychology, 3(4), 603608 
Horowitz, M., Adler, N., \& Kegeles, S. (1988). A scales for measuring the occurance of positive mood: A preliminary report. Psychomatic Medicine, 50, 277-483.

Holye, R.H. \& Panter, A.T. (1995). Writing about structural equation models. In R.H. Hoyle (ed.), Structural equation modeling: Concepts, issues, and applications. California: Sage Publications, Inc.

Holye, R.H. \& Smith, G.T. (1994). Formulating clinical research hypotheses as structural equation models: A conceptual overview. Journal of Consulting and Clinical Psychology, 62(3), 429-440.

Koelega, H. (1996). Sustained attention. In O. Neumann and A. F. Sanders (Eds.), Handbook of perception and action, volume 3: Attention (pp. 277-331). New York: Academic Press.

Koelega, H., Brinkman, J., Hendricks, L., \& Verbaten, M. (1989). Processing demands, effort, and individual differences in four different vigilance tasks. Human Factors, 31(1), 45-62.

Lang, P.J. (1995). The emotion probe: Studies of motivation and attention American Psychologist, 50(5), 372-385.

Leventhal, H., \& Tomarken, A.J. (1986). Emotion: Today's problems. Annual Review of Psychology, 37, 565-610.

Lezak, M.D. (1995). Neuropsychological Assessment. New York: Oxford University Press.

McKiernan, K.A. (1997). The effect of practice on auditory vigilance task performance. Unpublished master's thesis, University of Rhode Island. 
McKiernan, K.A., Purvenas, R., Tucker, V, \& Valentino, D. (1999, April). "Distractibility" during a vigilance test. . Poster session presented at the annual meeting of the Eastern Psychological Association, Providence, RI

McKiernan, K.A., Reeve, N. \& Valentino, D. (1997, May). A structural modeling description of vigilance using emotion and CPT measures. Poster session presented at the annual meeting of the American Psychological Society, Washington, DC.

McKiernan, K.A., Reeve, N. \& Valentino, D. (1996, July). The influence of emotion on measures of sustained attention. Poster session presented at the annual meeting of the American Psychological Society, San Francisco, CA.

McNair, D.M., Lorr, M., \& Droppelman, L. (1981). Profile of mood states manual. San Diego: Educational \& Industrial Testing Service.

Mirsky, A.F. (1996). Disorders of attention: A neuropsychological perspective. In G.R. Lyon \& N.A. Krasnegor (Eds). Attention, Memory, and Executive Function (pp. 71-95). Baltimore: Paul H. Brookes Publishing.

Mirsky, A.F., Anthony, B.J., Duncan, C.C, Ahearn, M.B., \& Kellam, S.G. (1991). Analysis of the elements of attention: A neuropsychological approach. Neuropsychology Review, 2(2), 109-145.

Moran, L.J., \& Mefferd, R.B. (1959). Repetative psychometric measures. Psychological Reports, 5, 269-275.

Mueller, R.O. (1996). Basic principles of structural equation modeling: An introduction to LISREL and EQS. New York: Springer. 
Parasuraman, R. (1984). Psychobiology of sustained attention. In D.H. Holding (Series Ed.) \& J.S. Warm (Vol. Ed.), Wiley series on studies in human performance: vol 4. Sustained attention in human performance (pp. 62-101). New York: John Wiley \& Sons, Ltd.

Parasuraman, R., \& Davies, D. (1977). A taxonomic analysis of vigilance performance. In R.R. Mackie (Ed.), Vigilance: theory, operational performance, and physiological correlates (pp. 559-574). New York: Plenum.

Prather, P. \& Kaplan, E. (unpublished manuscript). Attention and its disorders: Facts, physiology, and a theoretical framework.

Pribram, K.H., \& McGuiness, D. (1975). Arousal, activation, and effort in the control of attention. Psychological Review, 82(2), 116-149.

Raykov, T., Tomer, A., \& Nesselroade, J. R. (1991). Reporting stnuctural equation modeling results in Psychology and Aging: Some proposed guidelines. Psychology and Aging, 6(4), 499-503.

Reeve, N.J. (1997). A comparison of continuous performance tasks using cognitive versus sensory stimuli. Unpublished master's thesis, University of Rhode Island.

Revelle, W. (1992). Differences in personality and motivation. In A. Baddeley \& W. Weiskrantz (eds.), Attention: Selection Awareness and Control: A Tribute to Donald Broadbent (pp. 346-373). Oxford: Clarendon Press.

Rosvold, H.E., Mirsky, A.F., Sarason, I., Bransome, E.D., \& Beck, L.H. (1956). A continuous performance test of brain damage. Joumal of Consulting Psychology, 20(5). 343-350. 
See, J., Howe, S., Warm, J., \& Dember, W. (1995). Meta-analysis of the sensitivity decrement in vigilance. Psychological Bulletin, 117, 230-249.

Smith, K. (1996). A scoring program for a computerized performance task [Computer programming language]. University of Rhode Island.

SPSS Graduate Pack 9.0 for Windows. [Computer programming language]. SPSS Inc. Chicago.

Stern, RA. (1997). VAMS. Psychological Assessment Resources, Inc.

Stern, R.A., Arruda, J.E., Hooper, C.R., Wolfner, G.D. \& Morey, C.E. (1996) Visual analog mood scales to measure internal mood state in neurologically impaired patients: Description and initial validity evidence. Aphasiology.

Stroop, J.R. (1935). Studies of interference in serial verbal reactions. Journal of Experimental Psychology, 18, 643-662.

Talland, G.A. (1965). Deranged Memory. Academic Press. New York.

Taylor, J.A. (1953). A personality scale of manifest anxiety. Journal of Abnormal Social Psychology, 48, 285-290.

Tomarken, A.J., Davidson, R.J., Wheeler, R.E., \& Doss, R.C. (1992). Individual differences in anterior brain asymmetry and fundamental dimensions of emotion. Journal of Personality and Social Psychology, 62(4), 676-687.

Tomporowski, P.D., \& Tinsley, V.F. (1996). Effects of memory demand and motivation on sustained attention in young and older adults. American Journal of Psychology, 109(2), 187-204. 
Tucker, D.M. \& Williamson, P.A. (1984). Asymmetric neural control systems in human self-regulation. Psychological Review, 91(2), I85-215.

Valentino, D.A., Arruda, J.E., \& Gold, S.M. (1993). Comparison of QEEG and response accuracy in good vs poorer performers during a vigilance task. International Journal of Psychophysiology, 15, 123-133.

Warm, J. S. (1984). An introduction to vigilance. In D.H. Holding (Series Ed.) \& J.S. Warm (Vol. Ed.), Wiley series on studies in human performance: vol 4. Sustained attention in human performance (pp. 1-14). New York: John Wiley \& Sons, Ltd.

Watson, D. \& Clark, L.A. (1992). Affects separable and inseparable: On the hierarchical arrangement of the negative affects. Journal of Personality and Social Psychology, 62, 489-505.

Watson, D. \& Clark, L.A. (1994). Manual for the positive and negative affect schedule - expanded form. The University of Iowa.

Watson, D. \& Clark, L.A., \& Tellegen, A. (1988). Development and validation of brief measures of positive and negative affect: The PANAS scales. Journal of Personality and Social Psychology 54(6), 1063-1070.

Watson, D. \& Tellegen, A. (1985). Toward a consensual structure of mood. Psychological Bulletin, 98(2), 219-235.

Williams, P. (1986). Processing demands, training, and the vigilance decrement. Human Factors, 28(5), 567-579. 
Table 1. Description of Transformation Calculations for All Model Variables

Variable

Focused Attention (PSOM1)

Productivity (PSOM2)

Restful Repose (PSOM4)

Drive

Reward

Number Cancellation (NC)

Tense

Tired

Positive Affect (PA)

Negative Affect (NA)

Fatigue

Joviality

Sadness

Serenity

Accuracy (ACC)

Reaction Time (RT)

\# False Alarms (FA)
Calculation(s)

$* 10$

* 10

*10

$\mathrm{X}^{2}, \div 10$

$\mathrm{X}^{2}, \div 10$

$\div 10$

$\mathrm{SQRT},{ }^{*} 10$

$\div 10$

n/a

$\ln ,{ }^{*} 10$

$n / a$

$n / a$

$\ln , * 10$

$\mathrm{n} / \mathrm{a}$

reflect, $\ln ,{ }^{*} 10$

$\div 10$

$\ln , * 10$

Note: $S Q R T=$ square root, $l n=$ natural $\log , n / a=$ not applicable (no transformation required) 


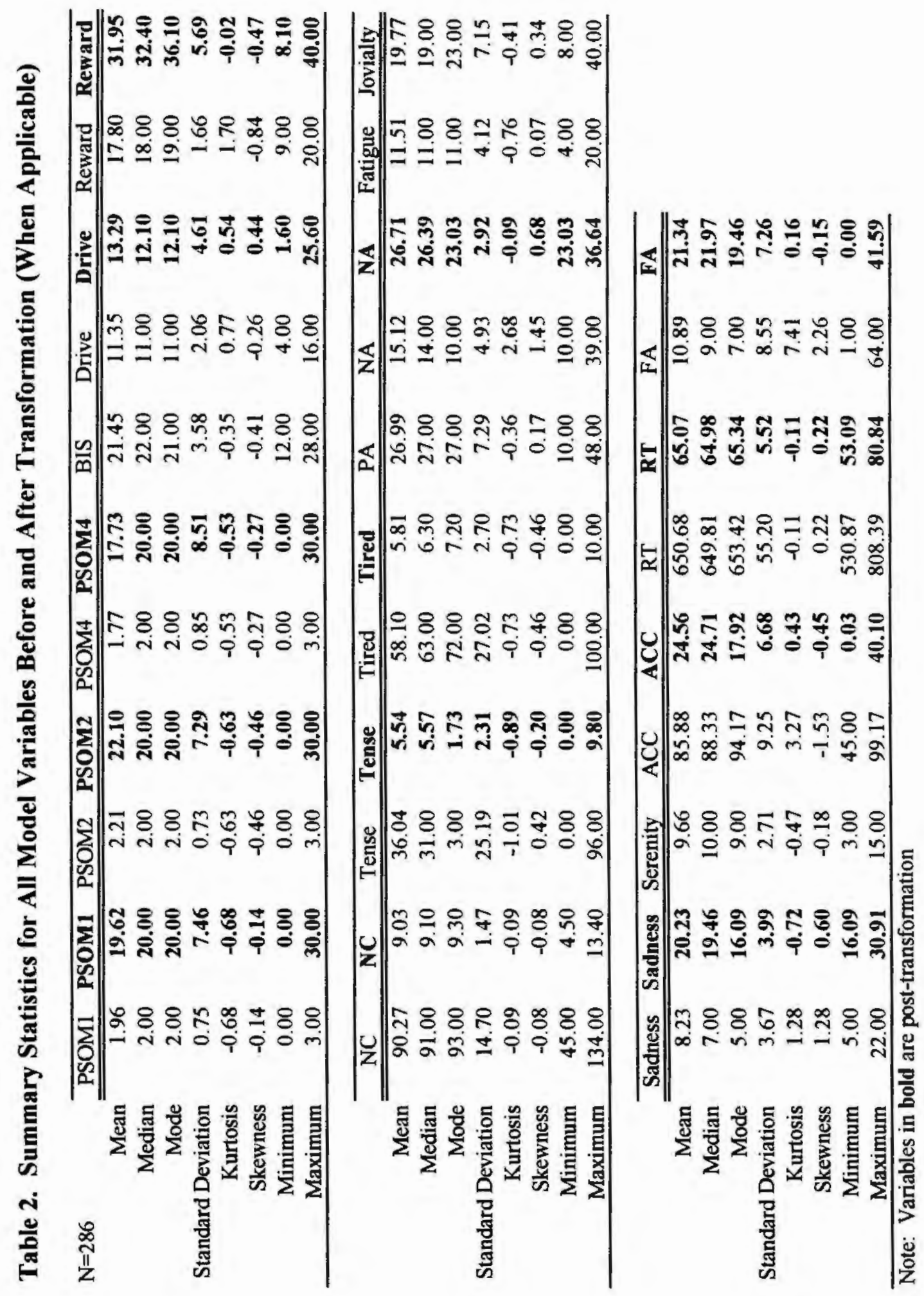




\begin{tabular}{|c|c|c|c|c|}
\hline 定 & 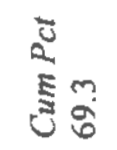 & 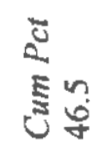 & $\frac{j}{5}$ & 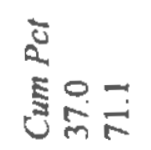 \\
\hline 8 & 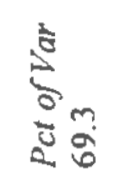 & $\sum_{5}^{5}$ & $\stackrel{5}{\frac{5}{5}}$ & 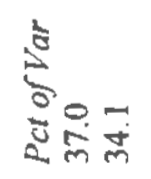 \\
\hline
\end{tabular}
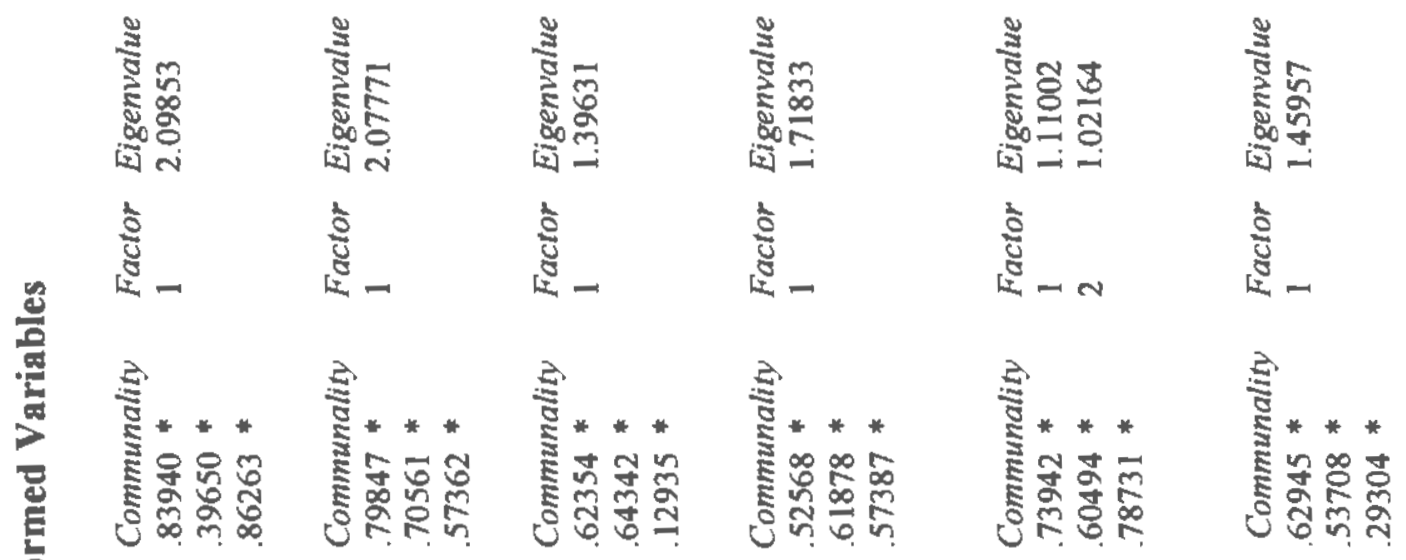

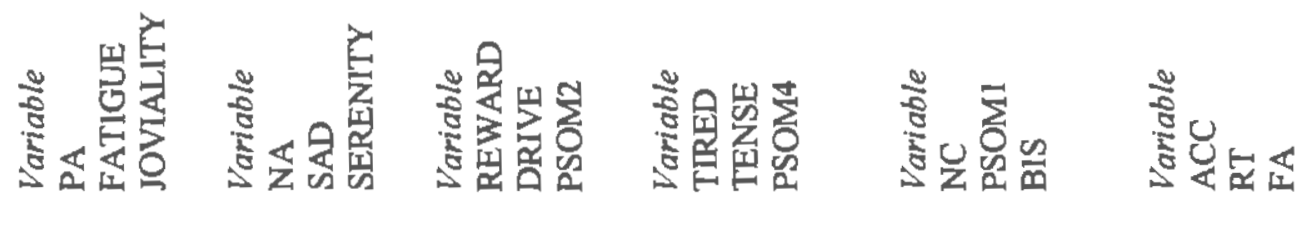

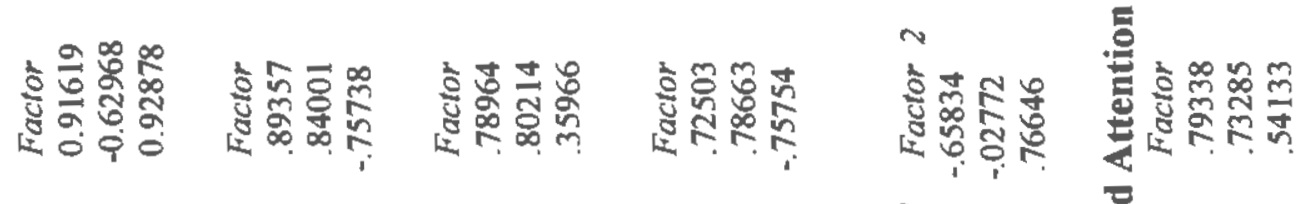
5

这
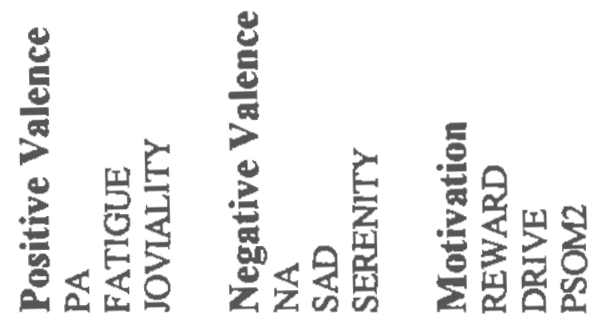

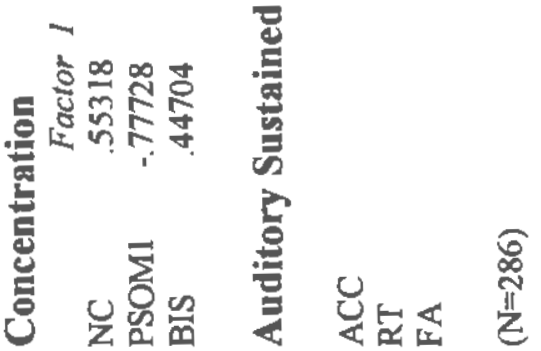




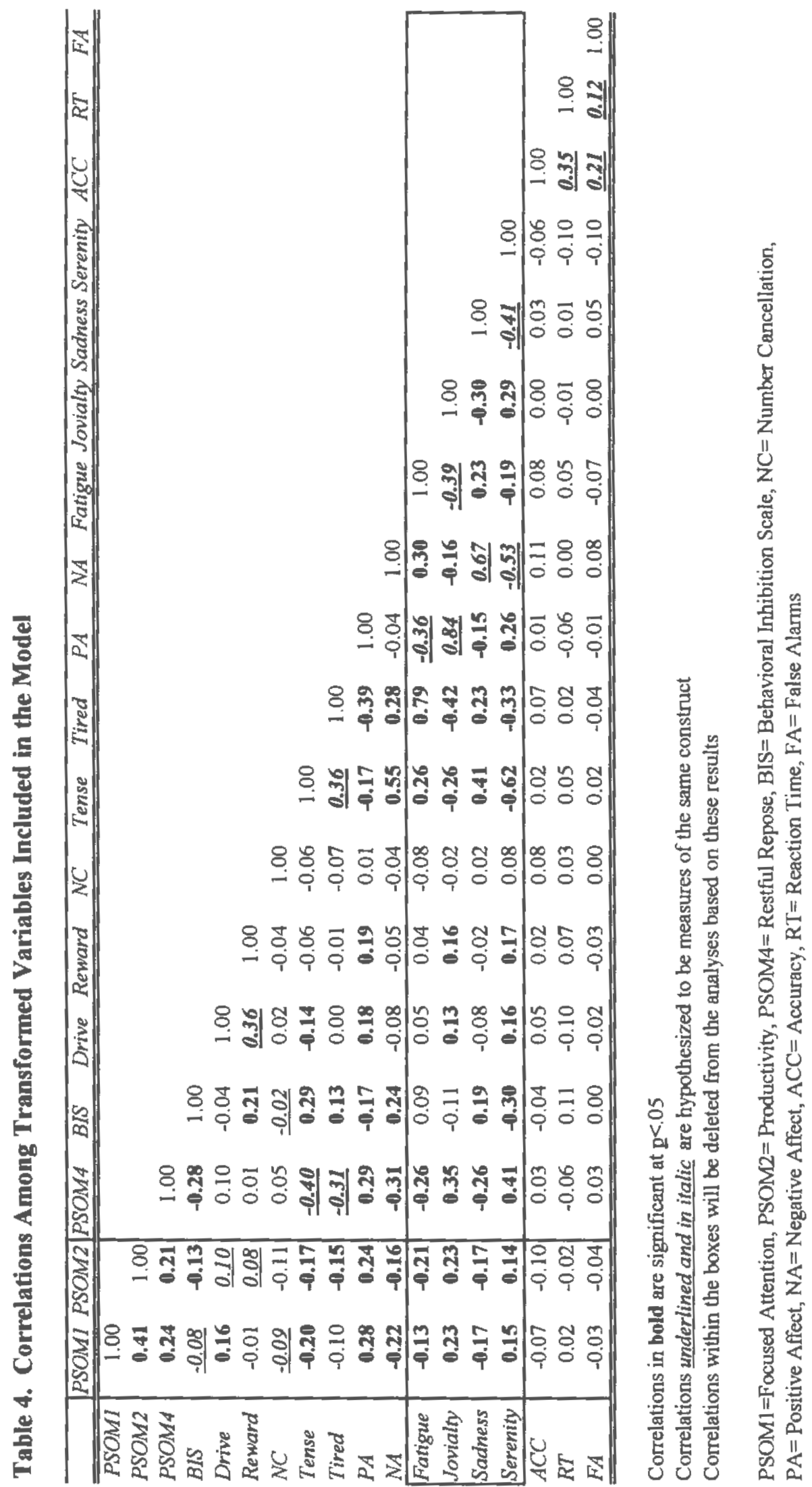


Table 5. Paired T-TEST Results for Reaction Time Data - Minutes 5-8 versus Minutes 13-16

$\begin{array}{lllllll} & \text { Mean } & \text { Std Dev. } & \text { Correlation } & \text { d } & \text { Significance } \\ \text { RT2 } & 677.97 & 64.43 & & & & \\ & & & .76 & 3.13 & 307 & .002 \\ \text { RT4 } & 669.78 & 67.04 & & & & \end{array}$

Note: RT2 $=$ minutes 5-8; RT4= minutes $13-16$; mean values are in milliseconds; $\mathrm{N}=308$ (full sample) 


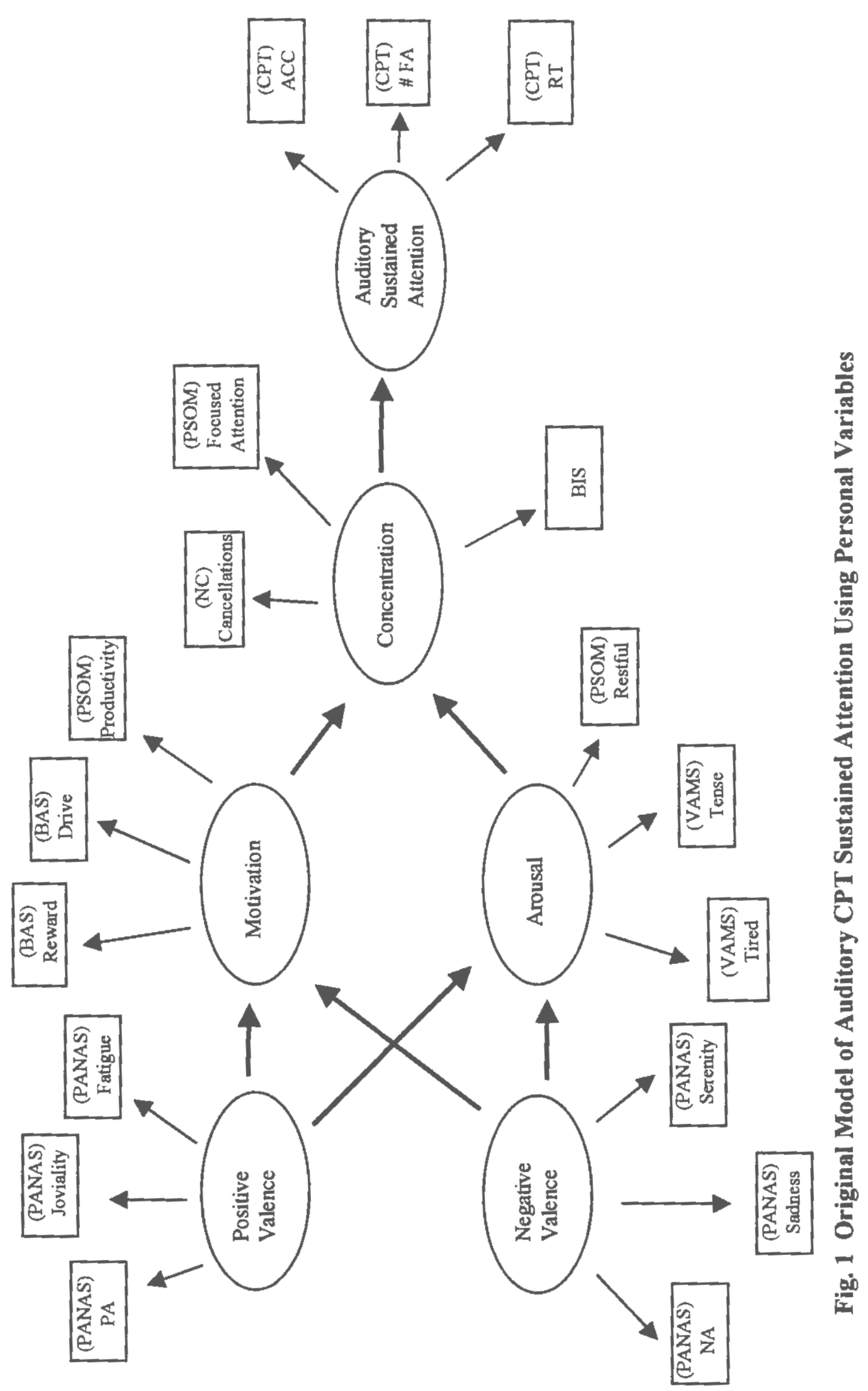




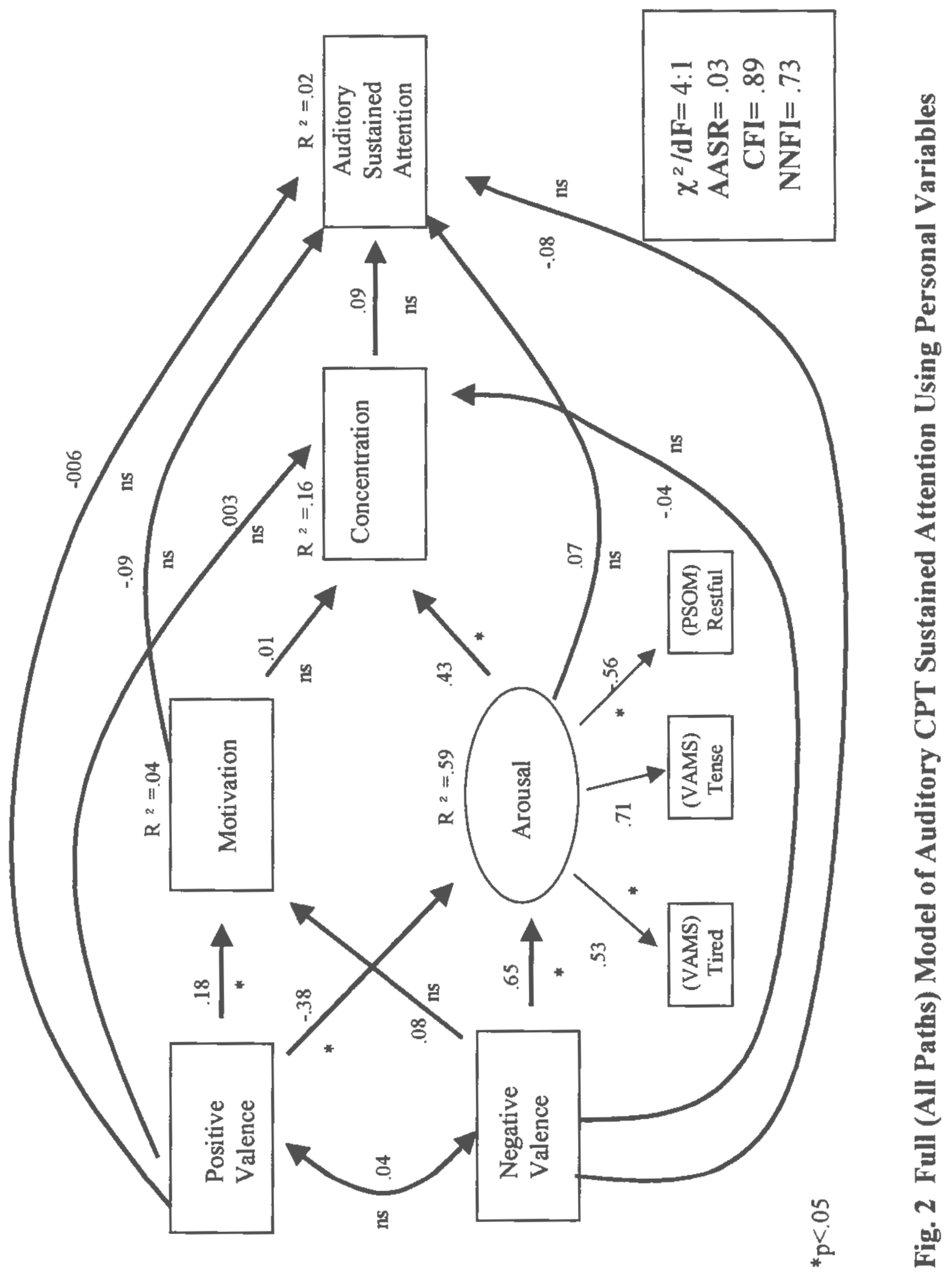




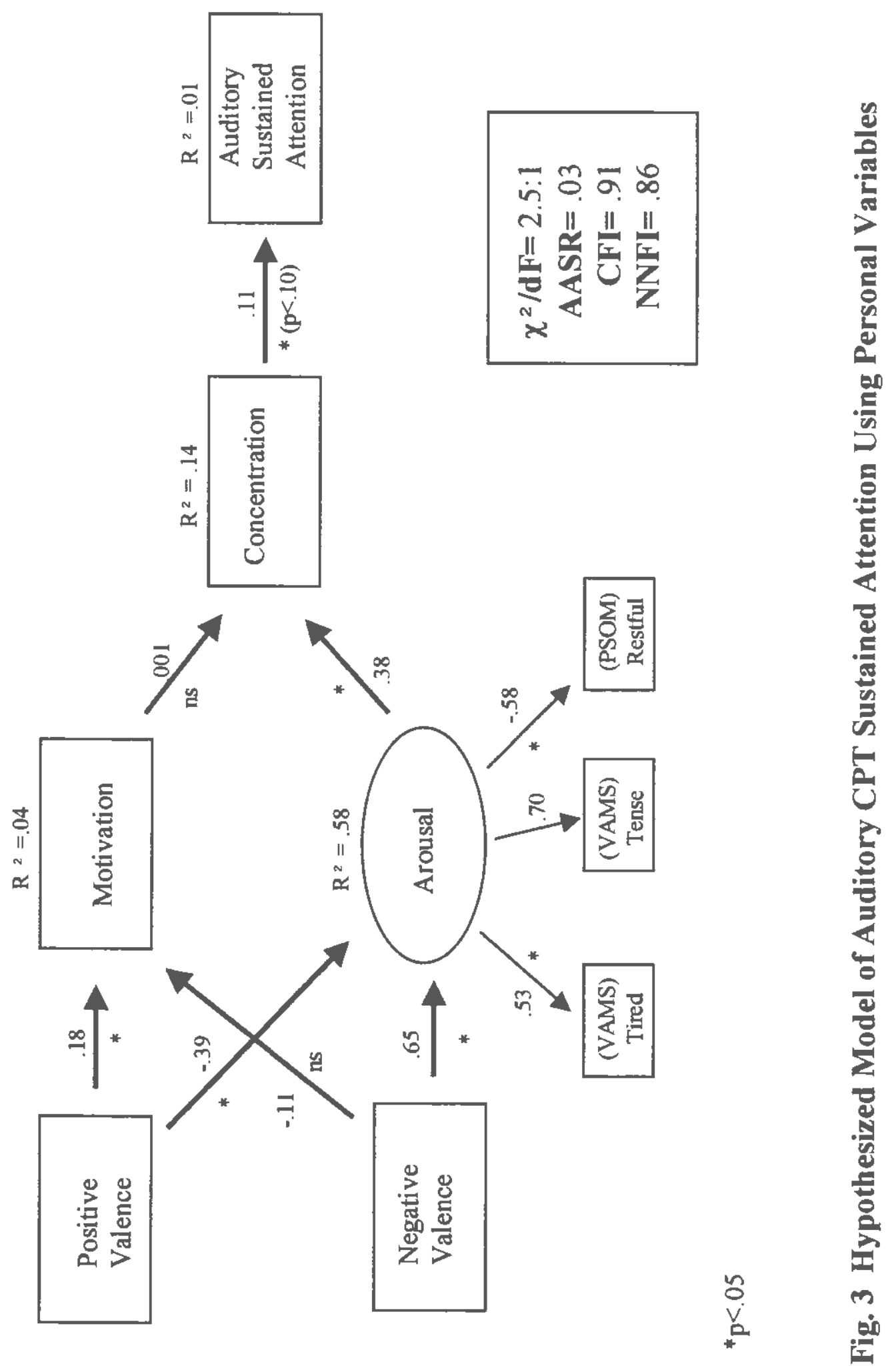




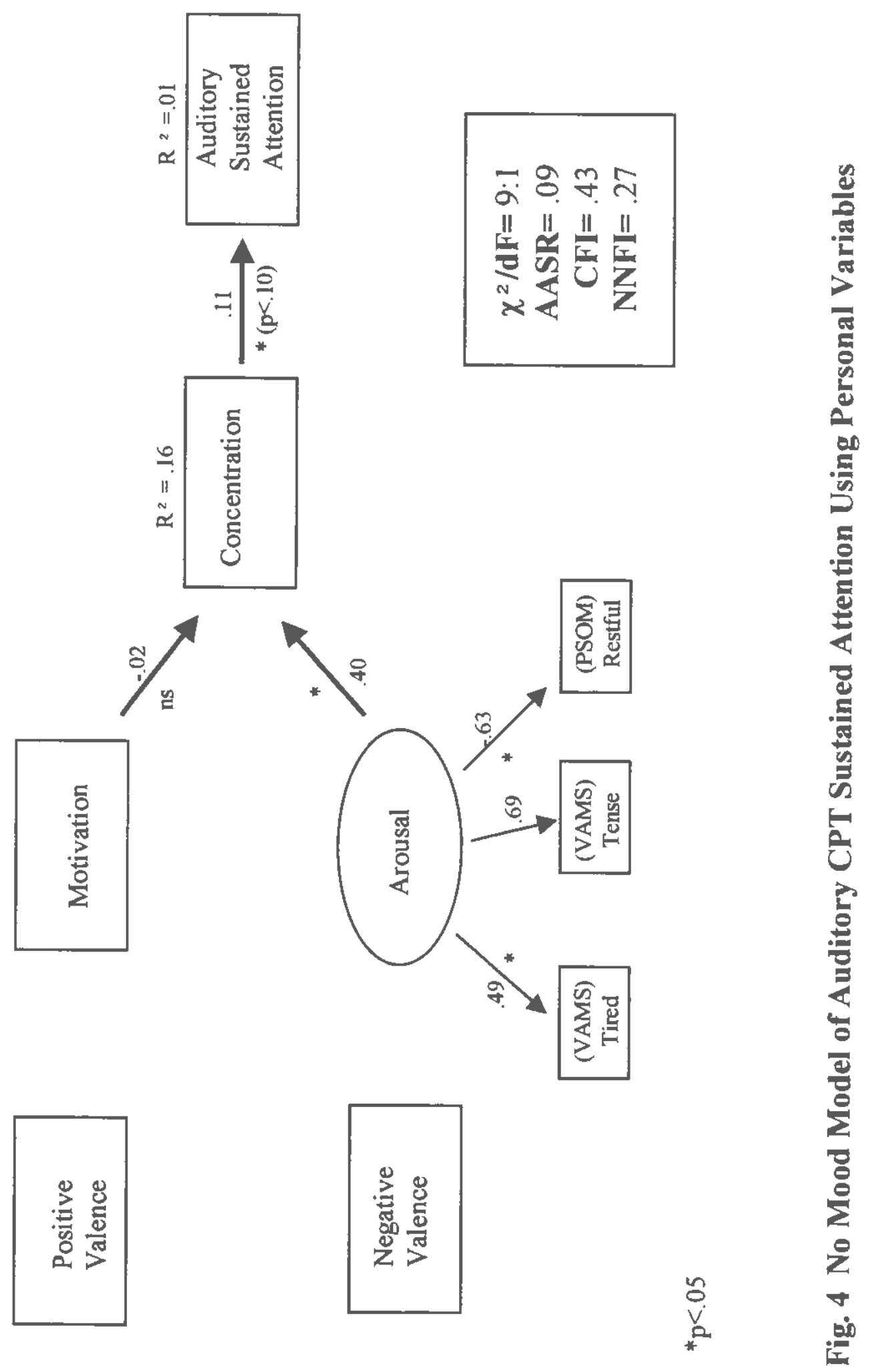




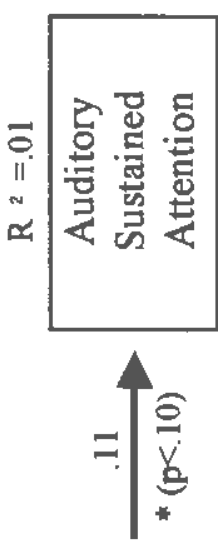

焉

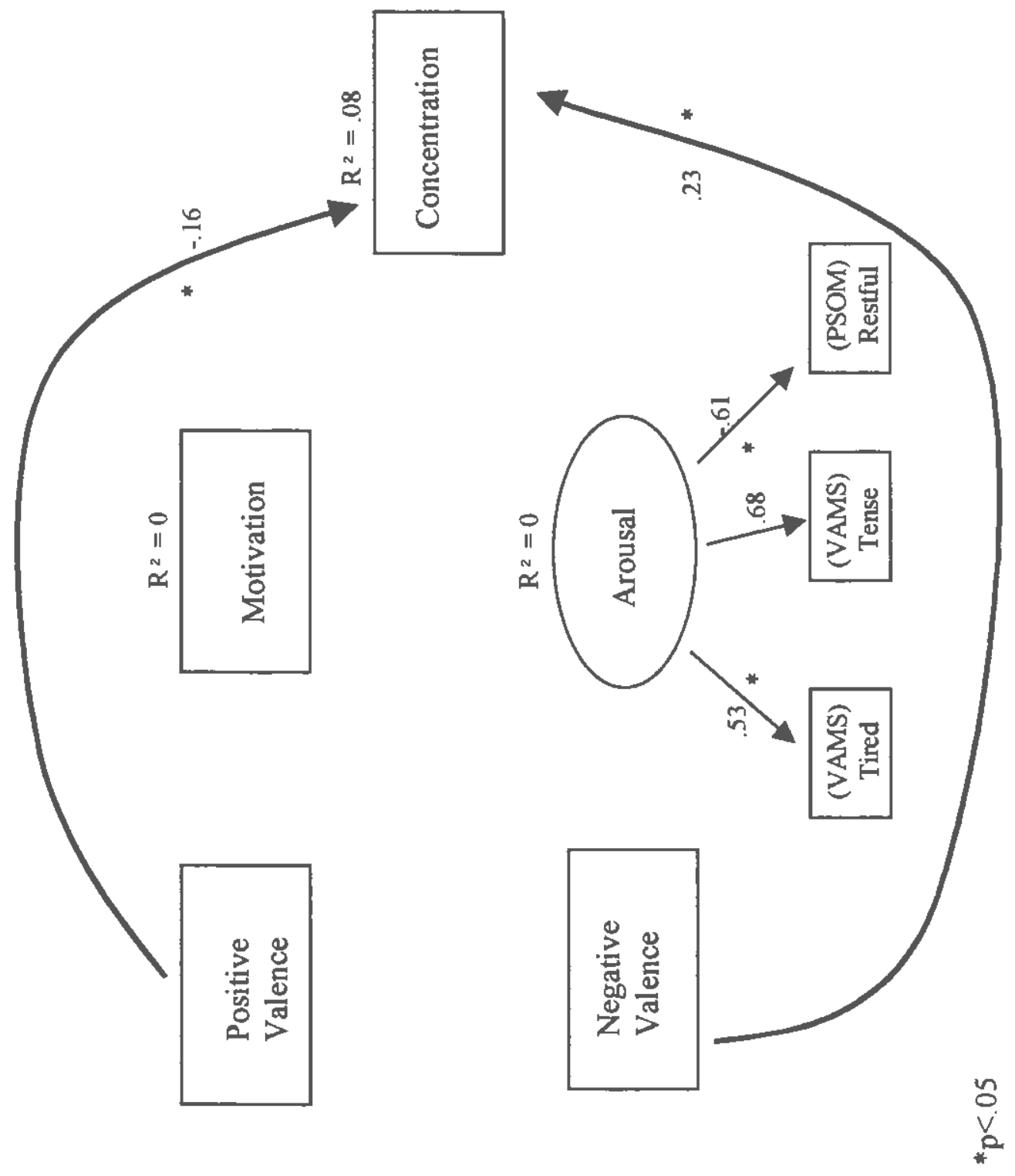

送

它

:

4

\% 


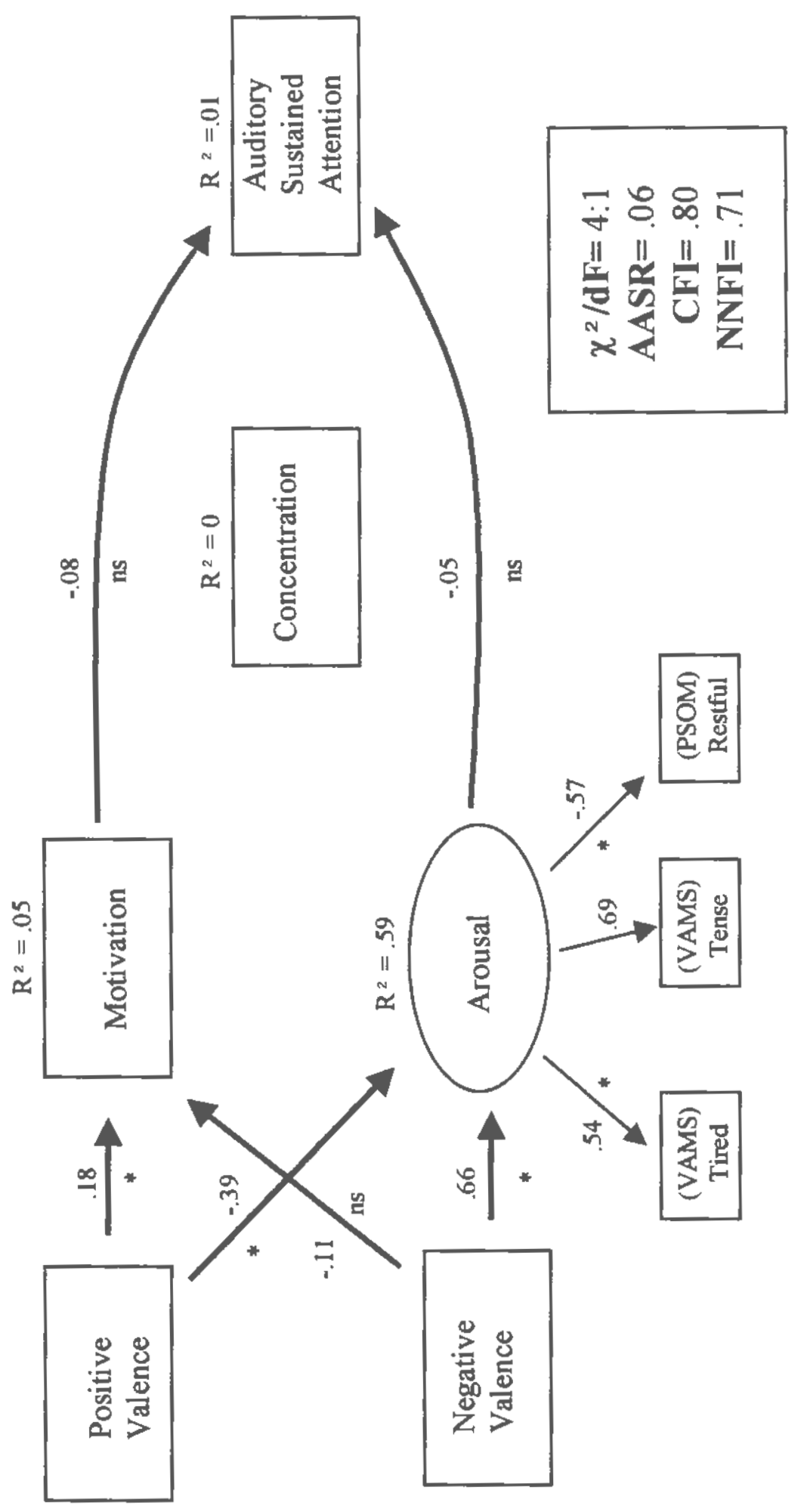

告 


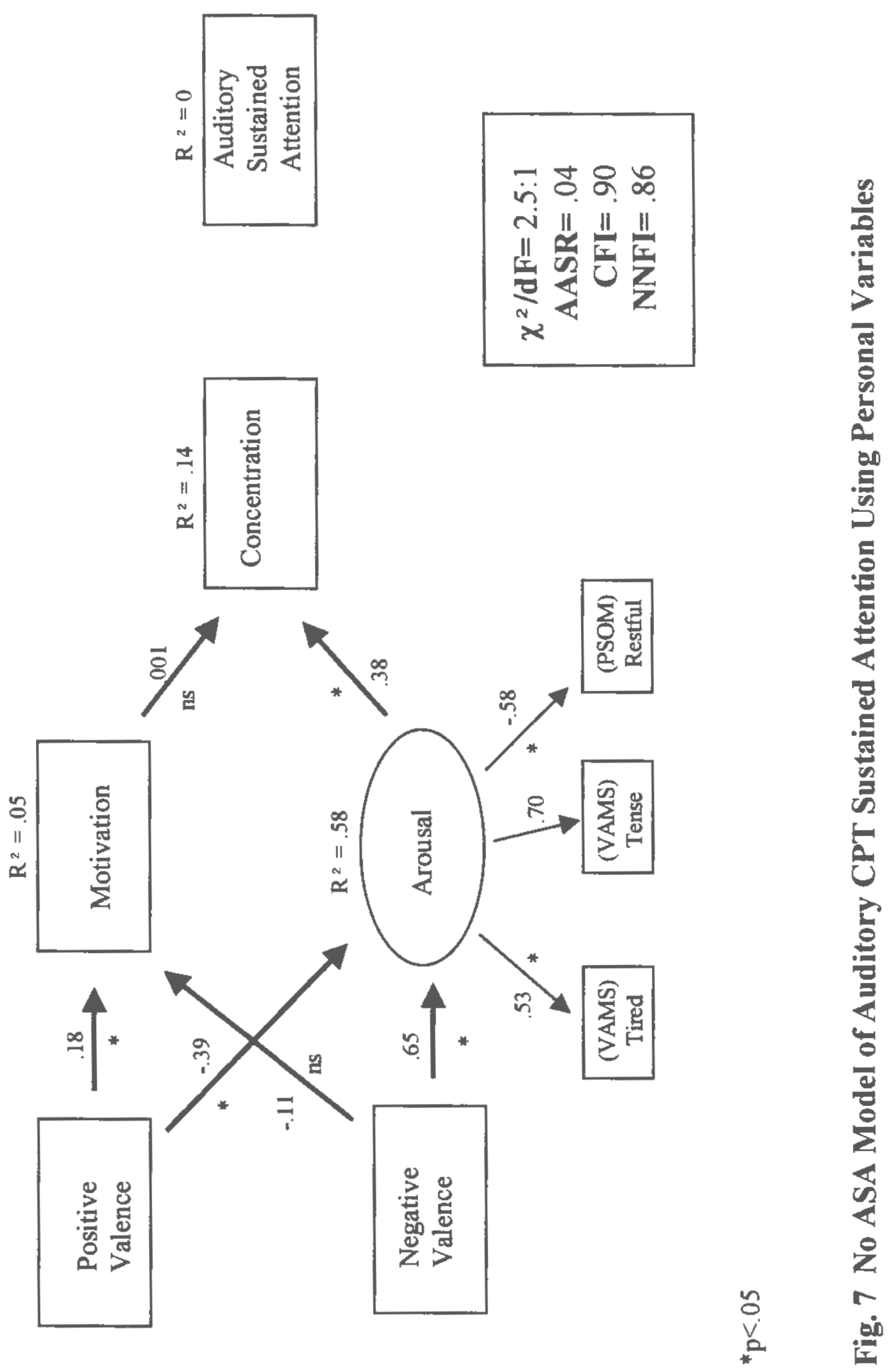




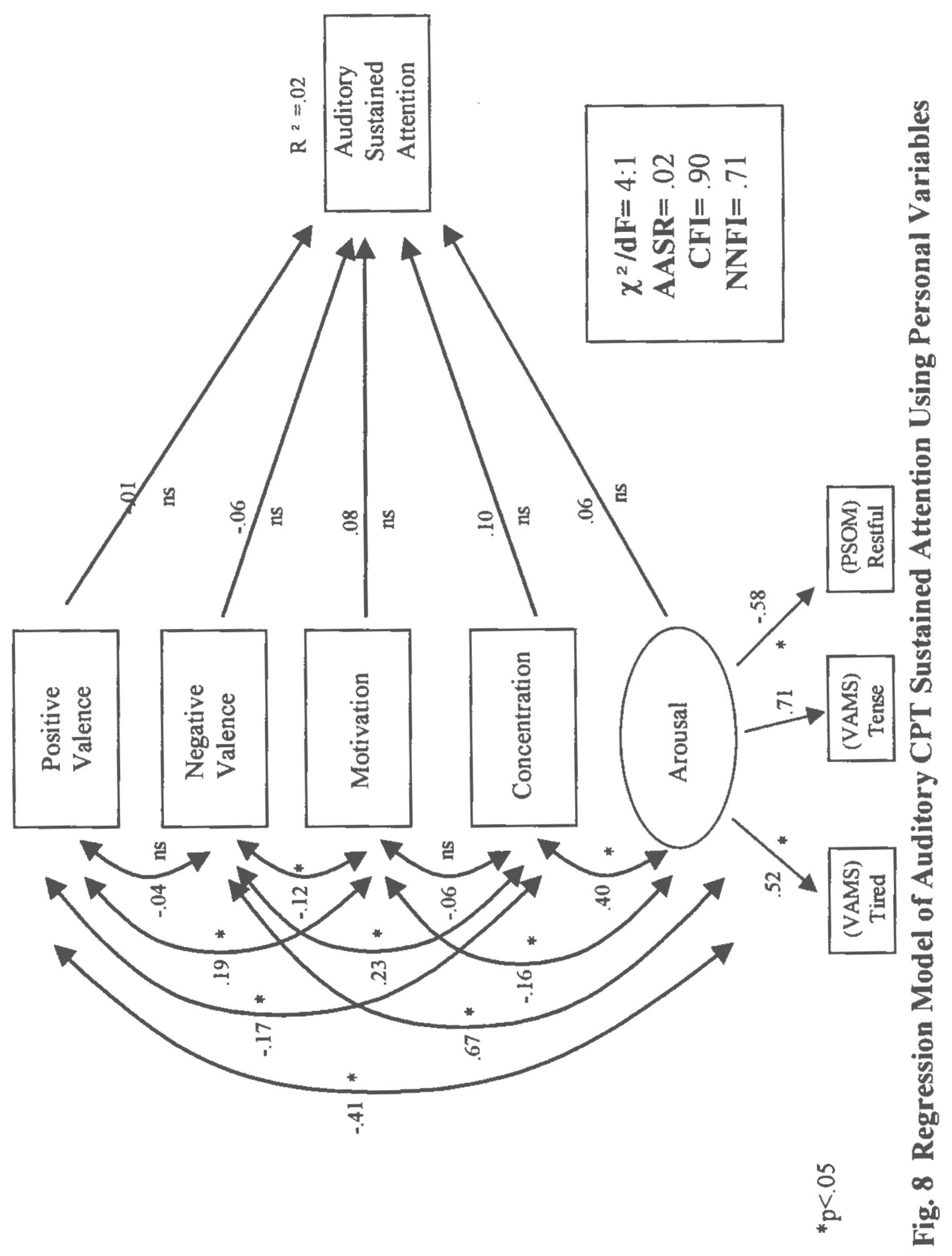


Appendix A

PANAS- $X$

$\mathrm{ID \#}$

This scale consists of a number of words and phrases that describe different feelings and emotions. Read each item and then mark the appropriate answer in the space next to that word. Indicate to what extent you feel this way right now (that is, at the present moment). Use the following scale to record your answers:

1

very slightly

or not at all

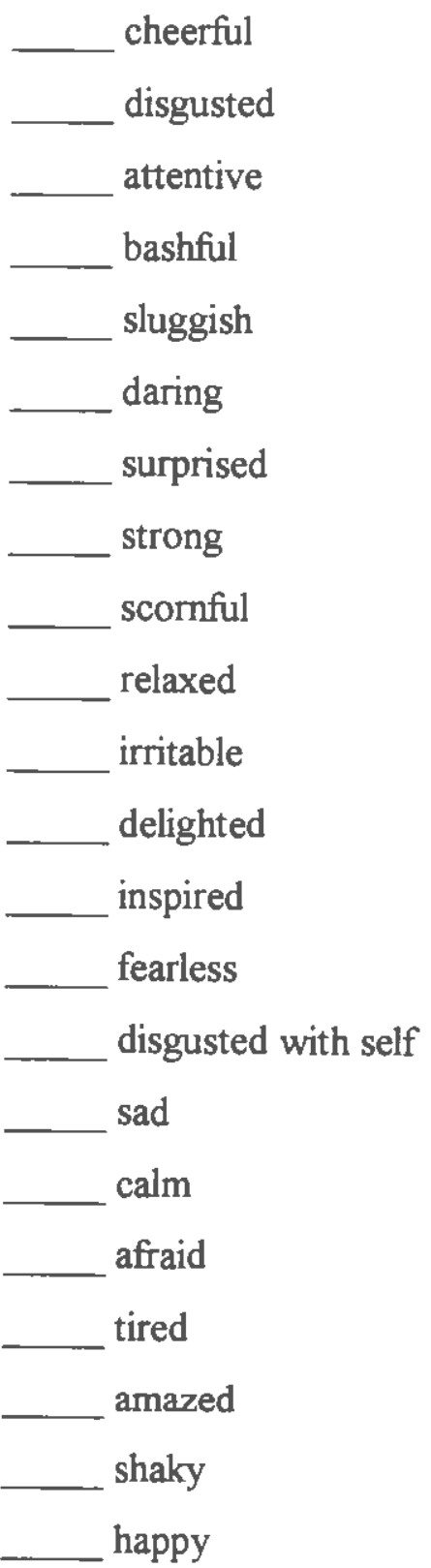

3 moderately alone alert upset angry timid bold blue shy active guilty joyful nervous lonely sleepy excited hostile proud jittery lively ashamed at ease scared

\section{5} quite a bit extremely 
Appendix B

BIS/BAS Scales

ID\#

Each item of this questionnaire is a statement that a person may either agree with or disagree with. For each item, indicate how much you agree or disagree with what the item says. Please respond to all the items; do not leave any blank Choose only one response to each statement. Please be as accurate and as honest as you can be. Respond to each item as if it were the only item. That is. don't wory about being "consistent" in your responses. Choose from the following four response options:

$1=$ very true for me

2 = somewhat true for me

$3=$ somewhat false for me

$4=$ very false for me

1. A person's family is the most important thing in life.

2. Even if something bad is about to happen to me. I rarely experience fear or nervousness.

3. I go out of my way to get things I want.

4. When I'm doing well at something, I love to keep at it.

5. I'm always willing to try something new if I think it will be fun.

6. How I dress is important to me.

7. When I get something I want, I feel excited and energized.

8. Criticism or scolding hurts me quite a bit.

9. When I want something, I usually go all-out to get it.

10. I will often do things for no other reason than they might be fun.

11. It's hard for me to find the time to do things such as get a haircut.

I2. If I see a chance to get something I want, I move on it right away.

13. I feel pretty worried or upset when I think or know somebody is angry at me.

14. When I see an opportunity for something I like, I get excited right away.

15. I often act on the spur of the moment.

16. If I think something unpleasant is going to happen, I usually get pretty "worked up".

17. I often wonder why people act the way they do.

I8. When good things happen to me, it affects me strongly.

19. I feel worried when I think I have done poorly at something important.

20. I crave excitement and new sensations.

21. When I go after something, I use a "no holds barred" approach.

22. I have very few fears compared to my friends.

23. It would excite me to win a contest.

24. I worry about making mistakes. 
Appendix C

Number Cancellation Task

ID\#

To complete this task, you must cancel (draw a line through) the target numerals. The number that is circled at the beginning of each line is the target number for that line only. Work as quickly as you can, but still be accurate. Start at the first row and complete each row in order (i.e., don't skip any lines). Begin when the experimenter tells you to and stop when they indicate that time is up. Note: there are two pages of numbers.

Example: (8) 25176\&59\$251

(6) 82043878773304488692836438776 (10) 46049346814220517242021192352 (2) 81294347094564257525706742597 (8) 64238183520398910273429596041 (1) 32495852581893681645890217542 (7) 54541735286705504838204848720 (3) 85078067295658052319493200173 (1) 79127690143723645401267369586 (9)79020729018341779154288060547 (2) 48367250147047211901465773103 (7) 99034576485249507984949618572 (8) 40128647819083718745043658551 (5) 85242025017628742394816266105 (3) 85907072802734894168398702661 (1) 32418983591680978177756250798 (1) 15682968519014667867991039241 (7) 96153871146009753621248018702 (6) 09167321215853239804721693634 (2) 08398267155006088294737151360 (4) 52388614931616520093564665292 (3) 25277429320056945619253711306 (8) 20118754274453248124577095667 (9) 40606658446324139810644942604 (1) 01568296826748962984519033071 (5) 77325766590773421842354471789 
(3) 44193284088235619678651723966 (4) 57644217717269086922667612941 (1) 48133081526633618480728050518 (6) 92267129611481330815263368184 (8) 07218050592851441759054318341 (7) 79150017640143549002937909280 (2) 16071002073749288060594168307 (4) 22843722027047393090533151743 (5) 67829605010467054816528174179 (0) 90728172167102737492881635594 (1) 68307424816528174179094123009 (2) 95460432435541208519989130613 (5) 30201720733958962868653391808 (9) 90221301067970203125368814944 (3) 87232507989129254688470293897 (1)77880772951187176289380289813 (4) 64312988129718774938720250789 (7) 96153871146009753621248018702 (1) 01568296826748962984519033071 (6) 40143549002936909280678296054 (8) 05059285141721671027374928735 (981064494260497536212480187029 (2) 96825460437806520670817729571 (4) 81652817417909112300929546046 (5) 25217352396181073493688458483 


\section{Appendix D \\ Positive Sate of Mind Scale (PSOM)}

ID\#

This questionnaire is about the kind of satisfying sates of mind that you may have experienced in the last 7 days. Circle one response to each item according to these rough estimates:

$$
\begin{aligned}
& 0=\text { unable to have it } \\
& 1=\text { trouble in having it } \\
& 2=\text { limited in having it } \\
& 3=\text { have it well }
\end{aligned}
$$

1. Focused Attention: Feeling able to attend to a task you want or need to do, without many distractions from within yourself.

$\begin{array}{llll}0 & 1 & 2 & 3\end{array}$

2. Productivity: Feeling of being able to stay at work until a task is finished, do something new to solve problems, or express yourself creatively.

$\begin{array}{llll}0 & 1 & 2 & 3\end{array}$

3. Responsible Caretaking: Feeling that you are doing what you should do to take care of yourself or someone else.

$\begin{array}{llll}0 & 1 & 2 & 3\end{array}$

4. Restful Repose: Feeling relaxed, without distractions or excessive tension

$\begin{array}{llll}0 & 1 & 2 & 3\end{array}$

5. Sharing: Being able to commune with others in an empathetic, close way, as in talking, walking, going out, or just being together.

$$
\begin{array}{llll}
0 & 1 & 2 & 3
\end{array}
$$

Adapted from the Positive States of Mind Scale (PSOM), Horowitz, Adler \& Kegles (1988). 
Appendix E

Visual Analog Mood Scales (VAMS)
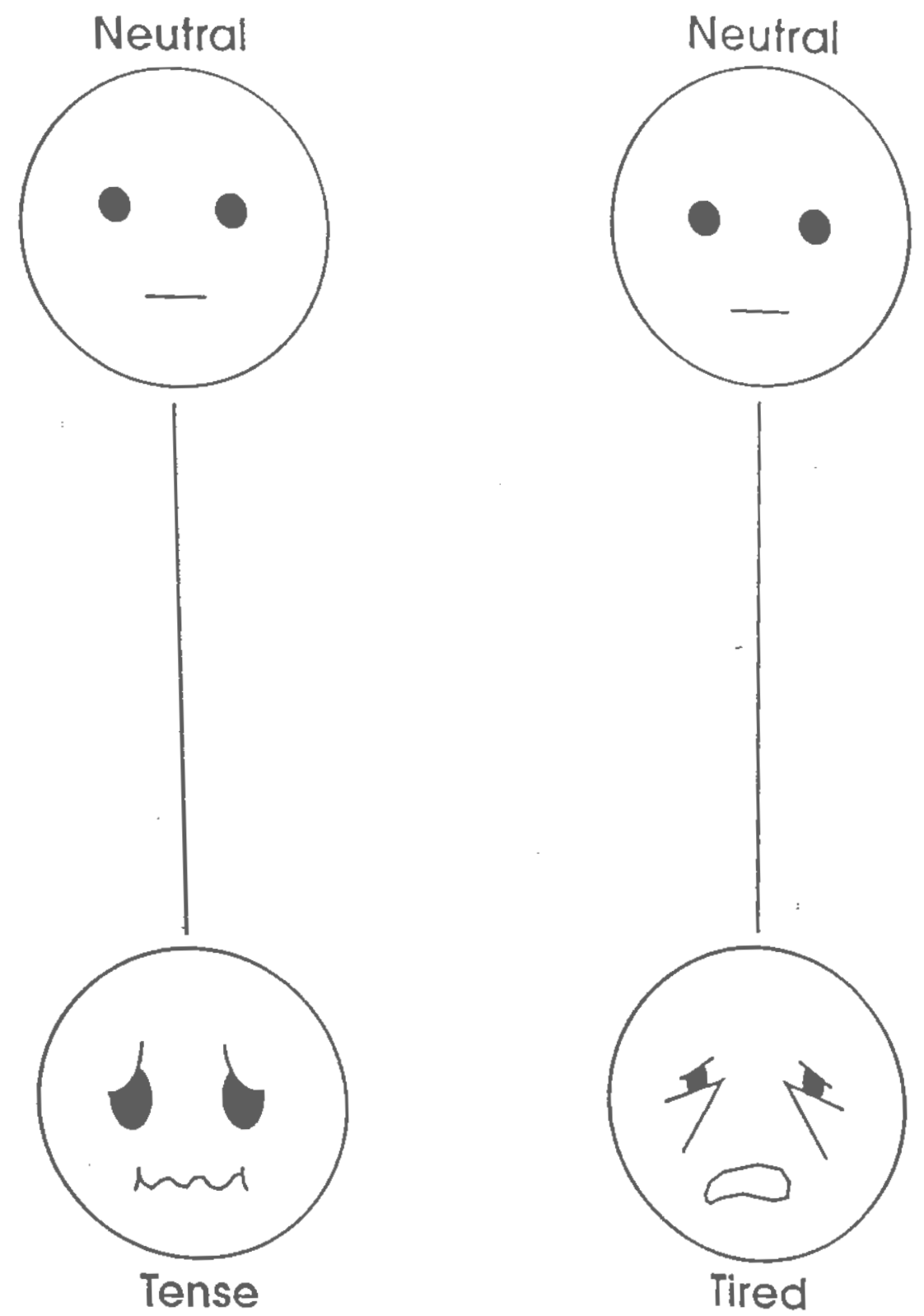


\section{Appendix F}

ID \#

\section{Informed Consent}

Subject Name Institution URI

Date of Birth Location Chafee 203

I have been asked to take part in a research project (described below). I should feel free to ask questions of the researcher. If I have more questions later, Dr. Valentino, the person mainly responsible for the study (874-4233), will discuss them with me. I may participate in the study, or I may change my mind and withdraw at any time. I understand that I will not receive payment for my participation, nor will I be penalized in any way if I withdraw.

Researchers at the University of Rhode Island Dept. of Psychology are conducting a study to observe the relationships between several personal characteristics and sustained attention. I understand that I will be asked to perform a simple mental task. This task, known as a Continuous Performance Task, involves listening to letters, words or sounds and responding to some of them by pressing a button. As part of this study, I may also be asked to fill out brief forms regarding personal information, such as my mood, and complete a number cancellation task.

This study will provide knowledge regarding the ways attention task performance can be impacted by how a person is feeling and how well they concentrate. This knowledge will help clinicians to do a better job recognizing and assessing attention test results.

My privacy will be protected during the course of the study. Though the computer disk on which my records are stored may contain a label with my Social Security number, my data will always be labeled with a number code available only to Dr. Valentino and Kristen McKiernan. I will not be identified in any publication resulting from this study.

If I am not satisfied with the way the study is performed, I may discuss my complaints with Dr. Valentino or with the Psychology Department Chairperson, Dr. Charles Collyer (874-2193), anonymously, if I choose. In addition, I may contact the office of the Vice Provost for Research, 70 Lower College Road, University of Rhode Island, Kingston, R.I., telephone: (401) 874-2635.

I have read the Consent Form. My questions have been answered. My signature on this form means that I understand the information, I am at least 18 years old, and I agree to participate in this study.

Signature

Investigator
Date

Date 


\section{BIBLIOGRAPHY}

Adler, N.E., Horowitz, M., Garcia, A., \& Moyer, A. (1998). Additional validation of a scale to assess positive states of mind, Psychosomatic medicine, 60, 26-32.

American Psychological Association. (1992). Ethical principals of psychologists and code of conduct. American Psychologist, 47,1597-1611.

Anderson, J.C, \& Gerbing, D.W. (1988). Structural equation modeling in practice: A review and recommended two-step approach. Psychological Bulletin, 103(3), 411423 .

Azar, B. (1995, November). Attitude affects memory, decisions, and performance. Monitor, p. 27.

Ballard, J.C. (1996). Computerized assessment of sustained attention: A review of factors affecting vigilance performance. Journal of Clinical and Experimental Neuropsychology 18(6), 843-863.

Bentler, P.M. (1990). Comparative fit indexes in structural models. Psychological Bulletin, 107(2), 238-246.

Bentler, P.M. (1995). EQS structural equations program. [Computer programming lanuage]. Encino, CA: Multivariate Software, Inc.

Bentler, P.M. (1995). EQS structural equations program manual. Encino, CA: Multivariate Software, Inc.

Bentler, P.M. \& Bonett, D.G. (1980). Significance tests and goodness-of-fit in the analysis of covariance structures. Psychological Bulletin, 88, 588-606. 
Bentler,P.M. \& Wu, E.J.C. (1995). EQS for window's users guide. Encino. CA: Multivariate Software, Inc.

Carver, C.S., \& White, T.L. (1994). Behavioral inhibition, behavioral activation and affective responses to impending reward and punishment: The BIS/BAS scales. Journal of Personality and Social Psychology, 67(2), 319-333.

Cohen, J. (1992). A power primer. Psychological Bulletin. 112, 155-159.

Cohen, R.A. \& O’Donnell, B. F. (1993). Physiological substrates of attention. In A.E. Puente \& C.R. Reynolds (Series Eds.) \& R.A. Cohen (Vol. Ed.), Critical issues in neuropsychology: The neuropsychology of attention (pp. 115-144). New York: Plenum Press.

Colby, C.L. (1991). The neuroanatomy and neurophysiology of attention. Journal of Child Neurology, 6, Supplement 1991, S90-S118.

Davies, D.R., \& Parasuraman, R. (1982). The psychology of vigilance. New York: Academic Press.

Fisk, A., \& Scerbo, M. (1987). Automatic and control processing approach to interpreting vigilance performance: A review and reevaluation. Human Factors, 29(6), $653-660$

Gray, J.A. (1972). The psychophysiological basis of introversion-extroversion: A modification of Eysenck's theory. In V.D. Nebylitsyn \& J.A. Gray (Eds.), The biological bases of individual behavior (pp. 182-205). San Diego, CA: Academic Press.

Gray, J.A. (1981). A critique of Eysenck's theory of personality. In: H.J. Eysenck (Ed.), A model for personality (pp. 246-276). Berlin: Springer-Verlag. 
Halperin, J.M., Sharma, V., Greenblatt, E., \& Schwartz, S. (1991). Assessment of the continuous performance test: Reliability and validity in a nonreferred sample. Psychological Assessment: A Journal of Consulting and Clinical Psychology, 3(4), 603608 .

Horowitz, M., Adler, N., \& Kegeles, S. (1988). A scales for measuring the occurance of positive mood: A preliminary report. Psychomatic Medicine, 50, 277-483.

Holye, R.H. \& Panter, A.T. (1995). Writing about structural equation models. In R.H. Hoyle (ed.), Structural equation modeling:Concepts, issues, and applications. California: Sage Publications, Inc.

Holye, R.H. \& Smith, G.T. (1994). Formulating clinical research hypotheses as structural equation models: A conceptual overview. Journal of Consulting and Clinical Psychology, 62(3), 429-440.

Koelega, H. (1996). Sustained attention. In O. Neumann and A. F. Sanders (Eds.), Handbook of perception and action, volume 3: Attention (pp. 277-331). New York: Academic Press.

Koelega, H., Brinkman, J., Hendricks, L., \& Verbaten, M. (1989). Processing demands, effort, and individual differences in four different vigilance tasks. Human Factors, 31(1), 45-62.

Lang, P.J. (1995). The emotion probe: Studies of motivation and attention American Psychologist, 50(5), 372-385.

Leventhal, H., \& Tomarken, A.J. (1986). Emotion: Today's problems. Annual Review of Psychology, 37, 565-610. 
Lezak, M.D. (1995). Neuropsychological Assessment. New York: Oxford University Press.

Mayer, J.D. \& Bremer, D. (1985). Assessing mood with affect-sensitive tasks. Journal of Personality Assessment, 49(1), 95-99

McKiernan, K.A. (1997). The effect of practice on auditory vigilance task performance. Unpublished master's thesis, University of Rhode Island.

McKiernan, K.A., Purvenas, R., Tucker, V, \& Valentino, D. (1999, April). "Distractibility" during a vigilance test. . Poster session presented at the annual meeting of the Eastern Psychological Association, Providence, RI

McKiernan, K.A., Reeve, N. \& Valentino, D. (1997, May). A structural modeling description of vigilance using emotion and CPT measures. Poster session presented at the annual meeting of the American Psychological Society, Washington, DC.

McKiernan, K.A., Reeve, N. \& Valentino, D. (1996, July). The influence of emotion on measures of sustained attention. Poster session presented at the annual meeting of the American Psychological Society, San Francisco, CA.

McNair, D.M., Lorr, M., \& Droppelman, L. (1981). Profile of mood states manual. San Diego: Educational \& Industrial Testing Service.

Mirsky, A.F. (1996). Disorders of attention: A neuropsychological perspective. In G.R. Lyon \& N.A. Krasnegor (Eds). Attention, Memory, and Executive Function (pp. 71-95). Baltimore: Paul H. Brookes Publishing.

Mirsky, A.F., Anthony, B.J., Duncan, C.C, Ahearn, M.B., \& Kellam, S.G. (1991). Analysis of the elements of attention: A neuropsychological approach.

Neuropsychology Review, 2(2), 109-145. 
Moran, L.J., \& Mefferd, R.B. (1959). Repetative psychometric measures. Psychological Reports, 5, 269-275.

Mueller, R.O. (1996). Basic principles of structural equation modeling: An introduction to LISREL and EQS. New York: Springer.

Parasuraman, R. (1984). Psychobiology of sustained attention. In D.H. Holding (Series Ed.) \& J.S. Warm (Vol. Ed.), Wiley series on studies in human performance: vol 4. Sustained attention in human performance (pp. 62-101). New York: John Wiley \& Sons, Ltd.

Parasuraman, R. (1998). The Attentive Brain. In R. Parasuraman (Ed.), The Attentive Brain (pp.3-15). Massachusetts: The MIT Press.

Parasuraman, R., \& Davies, D. (1977). A taxonomic analysis of vigilance performance. In R.R. Mackie (Ed.), Vigilance: theory, operational performance, and physiological correlates (pp. 559-574). New York: Plenum.

Parasuraman, R, Warm, J \& See, J. (1998). Brain systems of vigilance. In R. Parasuraman (Ed.), The Attentive Brain (pp.3-15). Massachusetts: The MIT Press.

Prather, P. \& Kaplan, E. (unpublished manuscript). Attention and its disorders: Facts, physiology, and a theoretical framework.

Pribram, K.H., \& McGuiness, D. (1975). Arousal, activation, and effort in the control of attention. Psychological Review, 82(2), 116-149.

Raykov, T., Tomer, A., \& Nesselroade, J. R. (1991). Reporting structural equation modeling results in Psychology and Aging. Some proposed guidelines. Psychology and Aging, 6(4), 499-503. 
Reeve, N.J. (1997). A comparison of continuous performance tasks using cognitive versus sensory stimuli. Unpublished master's thesis, University of Rhode Island.

Revelle, W. (1992). Differences in personality and motivation. In A. Baddeley \& W. Weiskrantz (eds.), Attention: Selection Awareness and Control: A Tribute to Donald Broadbent (pp. 346-373). Oxford: Clarendon Press.

Rosvold, H.E., Mirsky, A.F., Sarason, I., Bransome, E.D., \& Beck, L.H. (1956). A continuous performance test of brain damage. Journal of Consulting Psychology, 20(5), 343-350.

See, J., Howe, S., Warm, J., \& Dember, W. (1995). Meta-analysis of the sensitivity decrement in vigilance. Psychological Bulletin, 117, 230-249.

Smith, K. (1996). A scoring program for a computerized performance task [Computer programming language]. University of Rhode Island.

SPSS Graduate Pack 9.0 for Windows. [Computer programming language]. SPSS Inc. Chicago.

Stern, R.A. (1997). VAMS. Psychological Assessment Resources, Inc.

Stern, R.A., Amuda, J.E., Hooper, C.R., Wolfner, G.D. \& Morey, C.E. (1996). Visual analog mood scales to measure internal mood state in neurologically impaired patients: Description and initial validity evidence. Aphasiology.

Stroop, J.R. (1935). Studies of interference in serial verbal reactions. Journal of Experimental Psychology, 18, 643-662.

Talland, G.A. (1965). Deranged Memory. Academic Press. New York.- 
Taylor, J.A. (1953). A personality scale of manifest anxiety. Journal of Abnormal Social Psychology, 48, 285-290.

Tomarken, A.J., Davidson, R.J., Wheeler, R.E., \& Doss, R.C. (1992). Individual differences in anterior brain asymmetry and fundamental dimensions of emotion. Journal of Personality and Social Psychology, 62(4), 676-687.

Tomporowski, P.D., \& Tinsley, V.F. (1996). Effects of memory demand and motivation on sustained attention in young and older adults. American Journal of Psychology, 109(2), 187-204.

Tucker, D.M. \& Williamson, P.A. (1984). Asymmetric neural control systems in human self-regulation. Psychological Review, 91(2), 185-215.

Valentino, D.A., Arruda, J.E., \& Gold, S.M. (1993). Comparison of QEEG and response accuracy in good vs poorer performers during a vigilance task. International Journal of Psychophysiology, 15, 123-133.

Warm, J. S. (1984). An introduction to vigilance. In D.H. Holding (Series Ed.) \& J.S. Warm (Vol. Ed.), Wiley series on studies in human performance: vol 4. Sustained attention in human performance (pp. 1-14). New York: John Wiley \& Sons, Ltd.

Watson, D. \& Clark, L.A. (1992). Affects separable and inseparable: On the hierarchical arrangement of the negative affects. Joumal of Personality and Social Psychology, 62, 489-505.

Watson, D. \& Clark, L.A. (1994). Manual for the positive and negative affect schedule - expanded form. The University of Iowa. 
Watson, D. \& Clark, L.A., \& Tellegen, A. (1988). Development and validation of brief measures of positive and negative affect: The PANAS scales. Journal of Personality and Social Psychology 54(6), 1063-1070.

Watson, D. \& Tellegen, A. (1985). Toward a consensual structure of mood. Psychological Bulletin, 98(2), 219-235.

Williams, P. (1986). Processing demands, training, and the vigilance decrement. Human Factors. 28(5), 567-579. 